\title{
Evolution of the stable water isotopic composition of the rain sampled along Sahelian squall lines ${ }^{\dagger}$
}

\author{
Camille Risi, ${ }^{a *}$ Sandrine Bony, ${ }^{a}$ Francoise Vimeux, ${ }^{\text {bc }}$ Michel Chong $^{\mathrm{d}}$ and Luc Descroix ${ }^{\mathrm{e}}$ \\ ${ }^{a} L M D / I P S L, C N R S, U P M C$, Paris, France \\ ${ }^{\mathrm{b}}$ Institut de Recherche pour le Développement - Laboratoire HydroSciences Montpellier, France \\ ${ }^{c} I P S L$ - Laboratoire des Sciences du Climat et de l'Environnement (UMR CEA, CNRS, UVSQ), Gif-sur-Yvette, France \\ ${ }^{\mathrm{d}}$ Laboratoire d'Aérologie, Université de Toulouse and CNRS, Toulouse, France \\ ${ }^{\mathrm{e}}$ Laboratoire d'étude des Transferts en Hydrologie et Environnement, CNRS, Grenoble, France
}

\begin{abstract}
In the Tropics, the stable isotopic composition ( $\mathrm{HDO}, \mathrm{H}_{2}^{18} \mathrm{O}$ ) of precipitation is strongly modulated by convective activity. To better understand how convective processes impact the precipitation isotopic composition, we analyze the isotopic composition of rain collected during the passage of four squall lines over the Sahel (Niamey, Niger) in August 2006 during the African Monsoon Multidisciplinary Analysis (AMMA) campaign. The high-frequency sampling (5-10 $\mathrm{min}$ ) of the precipitation allows us to investigate the evolution of the precipitation isotopic composition in different phases of the squall lines. Despite a large variability among the different squall lines, some robust isotopic features appear: the $\mathrm{W}$ shape of the $\delta^{18} \mathrm{O}$ evolution and the deuterium excess decrease in the first part of the stratiform zone. To understand more quantitatively how convective processes impact the precipitation isotopic composition, a simple stationary two-dimensional transport model including a representation of cloud microphysics and isotopic fractionation is developed and forced by three-dimensional winds retrieved from the Massachusetts Institute of Technology (MIT) radar on 11 August 2006. The model reproduces the robust observed features and a large sensitivity to the squall-line dynamics. This model suggests that the main controlling factors of the isotopic evolution are (1) squall-line dynamics, especially the downward advection of air at the rear of the squall lines, affecting the vapour composition and, by isotopic equilibration, the subsequent precipitation composition and (2) rain re-evaporation. This suggests that water isotopes have the potential to better constrain squall-line dynamics and rain re-evaporation, and to evaluate the representation of convective processes in numerical models.
\end{abstract}

KEY WORDS rain evaporation; AMMA; convection

\section{Introduction}

Owing to mass and symmetry differences, stable water isotopes $\left(\mathrm{H}_{2}^{16} \mathrm{O}, \mathrm{HDO}, \mathrm{H}_{2}^{18} \mathrm{O}\right)$ are sensitive to phase changes and diffusive processes. Stable water isotopes have long been used in polar studies as proxies for climate and especially temperature changes. In the Tropics, however, the primary control of the isotopic composition of the precipitation is not temperature but precipitation amount (Dansgaard, 1964). A recent analysis using a single-column model including the Emanuel convective parametrization (Emanuel, 1991) suggests that the relationship between the enrichment in heavier isotopes and the precipitation rate, known at the monthly scale as the 'amount effect', is primarily controlled by rain re-evaporation (raindrops get more enriched as they re-evaporate), diffusive exchanges and the recycling of the boundary-layer vapour by depleted

\footnotetext{
${ }^{*}$ Correspondence to: Camille Risi, LMD/IPSL, CNRS, UPMC Paris, France. E-mail: camille.risi@lmd.jussieu.fr

This article was published online on 28 September, 2009. An error was subsequently identified. This notice is included in the online and prin versions to indicate that both have been corrected 18 January 2010 .
}

vapour from convective downdraughts generated by the rain re-evaporation (Risi et al., 2008a).

The intensity of convection and rain re-evaporation are known to exhibit a systematic evolution along the life cycle of individual convective systems (Houze, 1977; Zipser, 1977; Sherwood and Wahrlich, 1999). The temporal evolution of the rain isotopic composition in wellorganized convective systems is therefore likely to reveal the effect of these processes on the precipitation isotopic composition. To test this hypothesis, measuring the rain isotopic composition along squall lines in the Sahel is appealing: the Sahel is associated with both intense convective systems and strong re-evaporation (Chong and Hauser, 1990; Zahiri, 2007), because of the dryness of the air in the vicinity of the Sahara. Taupin and Gallaire (1998) noted a systematic evolution of the isotopic composition along squall lines in Niamey, Niger. A systematic evolution was also observed along convective systems in other regions (Celle-Jeanton et al., 2004; Barras and Simmonds, 2009) or along radial transects in tropical cyclones (Gedzelman et al., 2003; Fudeyasu et al., 2008). These studies identified a variety of processes controlling the observed isotopic evolution of the precipitation, such 
as (1) the origin of air masses (Taupin and Gallaire, 1998), (2) rain re-evaporation (Taupin and Gallaire, 1998; Barras and Simmonds, 2009), (3) condensation altitude (at higher condensation altitude, the vapour is more depleted due to previous condensation, and thus the condensate forming the precipitation is more depleted: Celle-Jeanton et al., 2004) and (4) diffusive exchanges between the low-level vapour and the raindrops that deplete the vapour (particularly efficient when the relative humidity is high: Gedzelman et al., 2003; Fudeyasu et al., 2008). However, the large number of processes potentially involved makes the details of the observed evolution difficult to interpret.

In this study, we take advantage of the second special observation period (15 July-15 September: SOP-2) of the African Monsoon Multidisciplinary Analysis (AMMA) campaign (Redelsperger et al., 2006; Janicot et al., 2008) to analyze the evolution of the isotopic composition of precipitation sampled along four squall lines in Niamey, Niger, in August 2006. The campaign offers a huge quantity of data documenting each system (radars, mobile facility from the Atmospheric Radiation Measurement (ARM) programme, in situ measurements, satellites), allowing a more detailed interpretation of isotopic data. In addition, three-dimensional (3D) winds have been retrieved from the Massachusetts Institute of Technology (MIT) radar data (Chong, 2009, this issue) for one of the squall lines sampled, on 11 August 2006.

The main goal of this study is thus to better understand the role of convective processes in controlling the precipitation isotopic composition, and more generally to explore what information may be learned from water isotopes regarding cumulus convection and atmospheric processes.

In section 2, we present and compare the evolution of the isotopic composition of the precipitation along four squall lines and suggest some processes to explain the isotopic evolution. In section 3, we focus on the 11 August squall line, on which a simple two-dimensional (2D) model of transport and microphysics is run: we first describe this model, and then use it to investigate what controls the isotopic composition along squall lines. A discussion and concluding remarks are given in section 4 .

\section{Data}

\subsection{Rainwater collection and isotopic analysis}

Rain from squall-line systems on $6,11,18$ and 22 August 2006 was sampled on the roof of the Institut de Recherche pour le Développement (IRD) building in Niamey $\left(13.53^{\circ} \mathrm{N}, 2.1^{\circ} \mathrm{E}\right)$, at about $3 \mathrm{~m}$ above the ground and with no nearby obstacles or vegetation. Rain re-evaporation in the pluviometer is strongly limited: the pluviometer is devised with this aim, the relative humidity of the surface air is always above $90 \%$ during rainfall and the precipitation never spends more than $30 \mathrm{~min}$ in the pluviometer. Every five minutes, we read the precipitation amount and collect precipitation samples from the pluviometer into $15 \mathrm{ml}$ bottles. When precipitation was weak, we waited until there was enough precipitation in the pluviometer to fill the bottle, increasing the time step up to $30 \mathrm{~min}$ at maximum.

The isotopic composition is expressed as an enrichment in heavier isotopes $\mathrm{HDO}$ or $\mathrm{H}_{2}^{18} \mathrm{O}$ relative to the Standard Mean Ocean Water (SMOW), denoted respectively by $\delta \mathrm{D}$ and $\delta^{18} \mathrm{O}$ :

$$
\delta=\left(\frac{R_{\text {sample }}}{R_{\text {SMOW }}}-1\right) \times 1000 .
$$

The $R$ notation denotes the ratio of the HDO or $\mathrm{H}_{2}^{18} \mathrm{O}$ mixing ratio over that of $\mathrm{H}_{2}^{16} \mathrm{O} ; R_{\text {sample }}$ and $R_{\text {SMOW }}$ are the ratio in the sample and the SMOW respectively. At first order, variations in $\delta \mathrm{D}$ are eight times those of $\delta^{18} \mathrm{O}$. The deviation from this behaviour is measured by the deuterium excess: $d=\delta \mathrm{D}-8 \delta^{18} \mathrm{O}$ (Dansgaard, 1964). Hereafter, we denote the $\delta^{18} \mathrm{O}$ and $d$ of the precipitation by $\delta^{18} \mathrm{O}_{\mathrm{p}}$ and $d_{\mathrm{p}}$.

All $\delta^{18} \mathrm{O}$ and $\delta \mathrm{D}$ measurements are performed with an accuracy of $\pm 0.05 \%$ and $\pm 0.5 \%$ o respectively, leading to an accuracy of about $\pm 0.7 \%$ for $d$.

\subsection{Variability and robust features among squall lines}

Snapshots of radar reflectivity from the MIT (Williams et al., 1992) and ARM mobile facility radars at Niamey airport (about $10 \mathrm{~km}$ from IRD), thermodynamical profiles from radio-soundings and the corresponding evolution of the observed precipitation rate, $\delta^{18} \mathrm{O}_{\mathrm{p}}$ and $d_{\mathrm{p}}$, for the four squall lines are plotted in Figures 1 and 2 . West African squall lines are convective systems aligned roughly in the north-south direction (Figure 1(a)) and propagating westwards. Therefore, assuming that the squall line is stationary, the temporal evolution at the sampling site corresponds to the spatial evolution along an east-west transect of the squall line. In agreement with previous squall-line studies (Houze, 1977), the precipitation rate features two maxima corresponding to the convective zone at the front and the stratiform zone at the rear, with a transition zone between these two maxima (Figure 2). Only for 22 August are the convective and stratiform zone not clearly defined.

The amplitude of isotopic variations along each squall line is of the order of $2-4 \%$ for $\delta^{18} \mathrm{O}_{\mathrm{p}}$ and $10-30 \%$ o for $d_{\mathrm{p}}$, demonstrating the strong influence of the different phases of convection on the isotopic composition. At first sight, the isotopic composition exhibits a large variability from one line to another, which is not surprising given the differences in the squall-line structures and dynamics, as illustrated by the radar reflectivity patterns (Figure 1(b)). However, squall lines show some consistent features, confirming the robust effect of some convective processes on the isotopic composition. In particular, $\delta^{18} \mathrm{O}_{\mathrm{p}}$ exhibits a 'W' shape: $\delta^{18} \mathrm{O}_{\mathrm{p}}$ decreases at the beginning of the squall line (the range of this decrease is $0.8-3.5 \%$ depending on the squall line), reaching a local minimum at the core of the convective zone. It increases then $(0.2-1.5 \%$ ) to reach a local maximum during the transition zone (or just after for 18 August). $\delta^{18} \mathrm{O}_{\mathrm{p}}$ decreases along the stratiform 
(a) C-band radar horizontal reflectivity maps
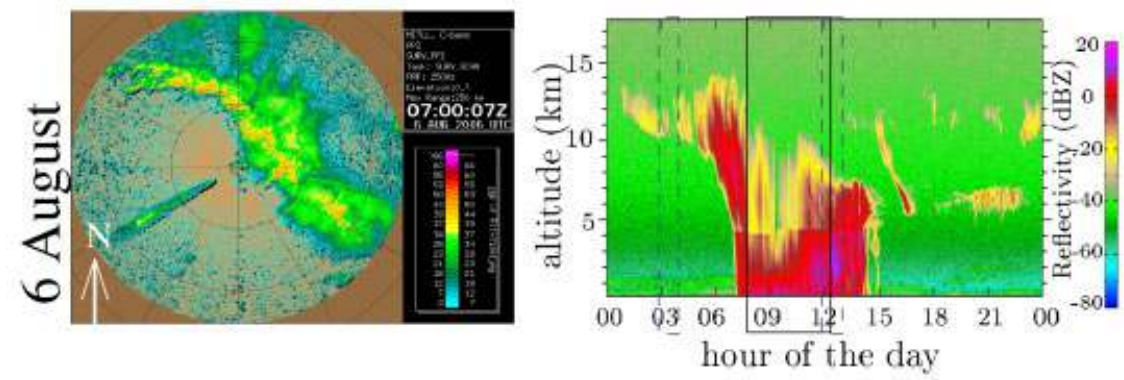

(b) W-band radar reflectivity profiles
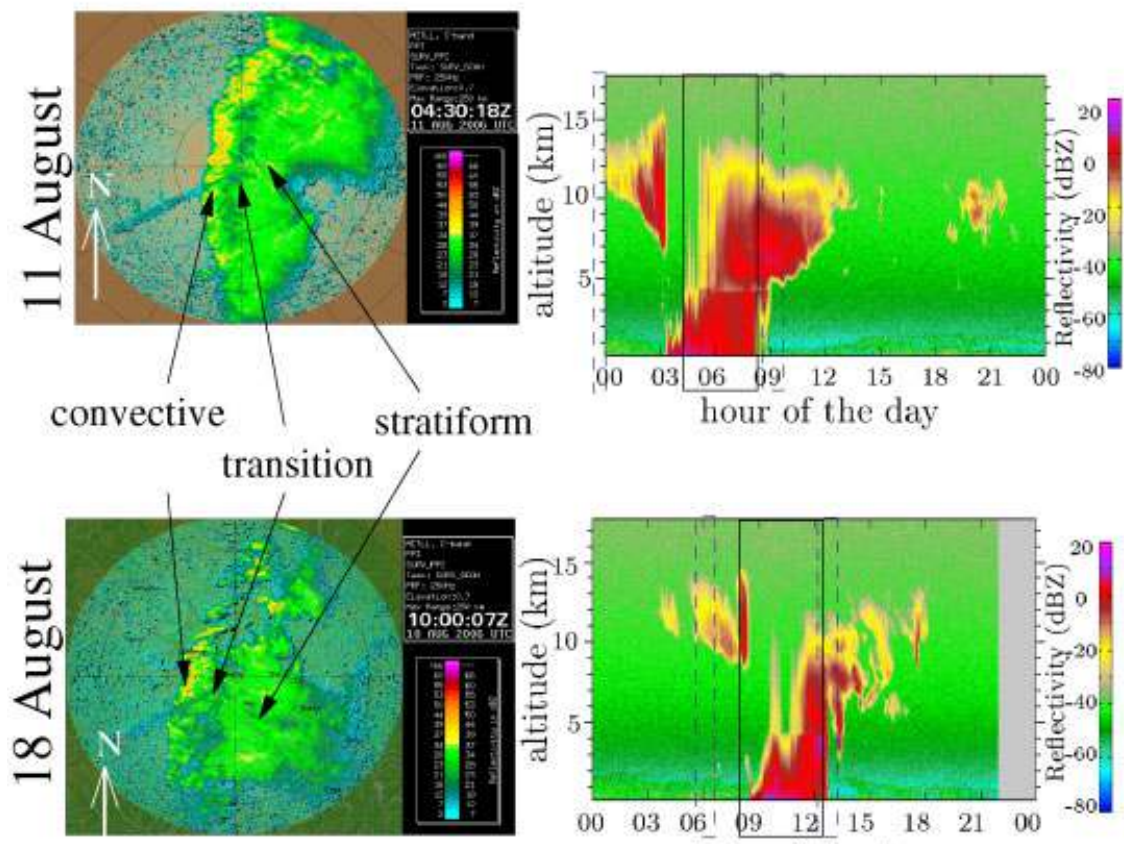

hour of the day
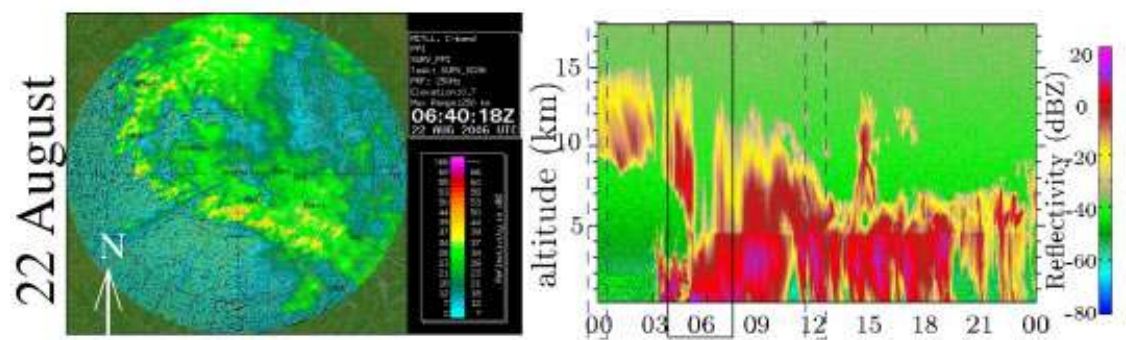

hour of the day (c) $\theta_{\mathrm{e}}$ and $\theta_{\text {es }}$ profiles

from radiosoundings
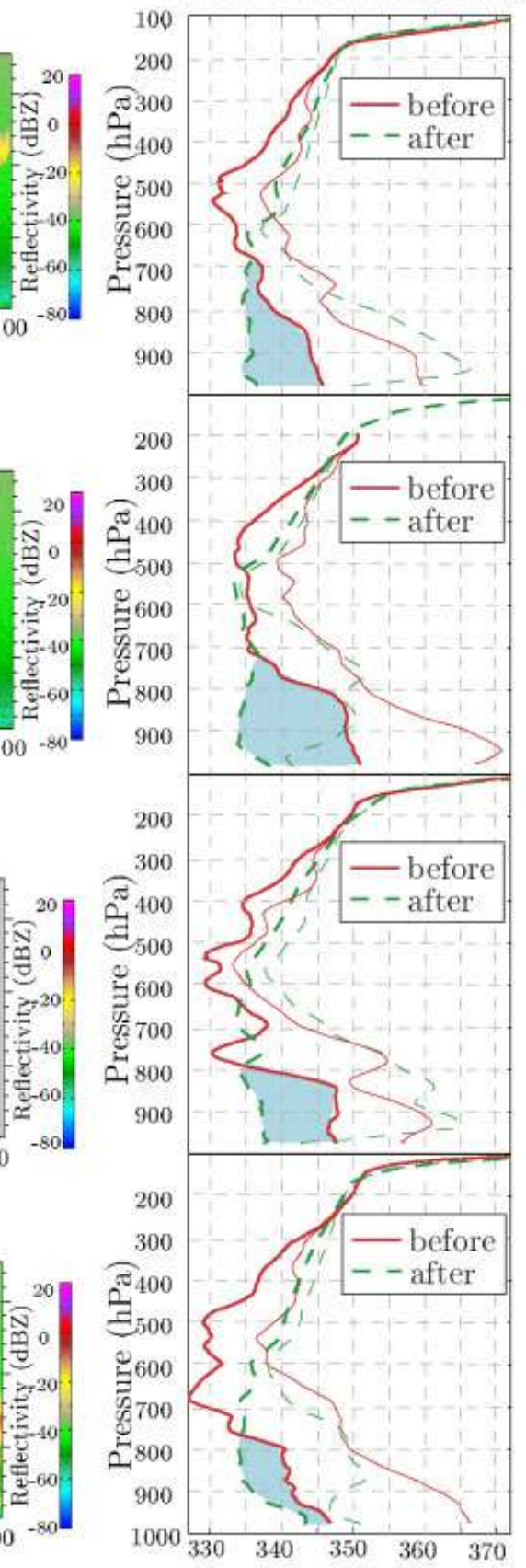

(K)

Figure 1. (a) Snapshots of C-band radar reflectivity maps for the four squall lines sampled, obtained by the MIT radar. (b) W-band reflectivity profiles obtained by the ARM radar. (c) Profiles of equivalent potential temperature $\left(\theta_{\mathrm{e}}\right.$, thick) and equivalent potential temperature at saturation $\left(\theta_{\mathrm{es}}\right.$, thin) from available radio-soundings before (solid/red) and after (dashed/green) the systems, giving information about the stabilization of the atmosphere by the system, notably through unsaturated downdraughts and mesoscale subsidence. The time of the radio-soundings is indicated in (b) by dashed/blue rectangles. A $20 \mathrm{hPa}$ smoothing filter was applied for an easier visualization. Radio-soundings performed with RS80-A sondes (6 August 0300 UTC and 11 August 0900 UTC) were corrected following Nuret et al. (2008). In (b), the time period over which the rain was sampled is indicated by black solid rectangles. This figure is available in colour online at www.interscience.wiley.com/journal/qj

zone $(0.5-1.5 \%)$, before increasing again at the end of the squall line $(0.2-1 \%$ o). Such a 'W' shape was also observed by Rindsberger et al. (1990) and by Taupin and Gallaire (1998) in a Niamey squall line.

The $d_{\mathrm{p}}$ value shows different evolutions in the convective zones (an increase for 6 and 18 August, a decrease for 22 August and stable for 11 August), but some robust features appear in the stratiform zone. It follows a similar pattern to $\delta^{18} \mathrm{O}_{\mathrm{p}}$, especially for 11 and 22 August: it decreases in the first portion of the transition zone (by 7-23\%o depending on the squall line), and then increases at the end of the squall line (by 5-15\%, except 

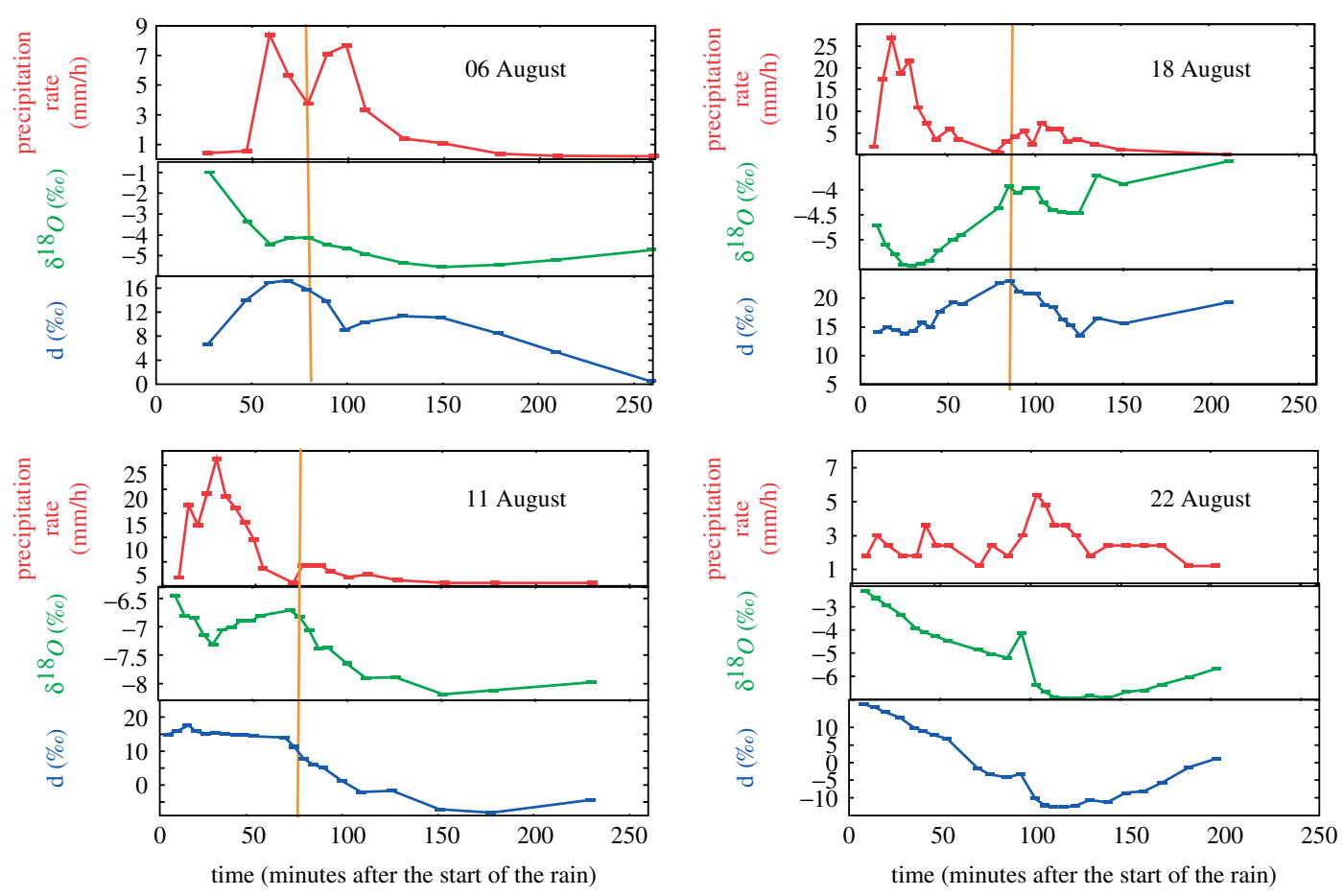

Figure 2. Evolution of precipitation rate, $\delta^{18} \mathrm{O}$ and $d$-excess along the four squall lines. The vertical/orange line indicates the transition zone (defined as the local precipitation minimum between the convective and stratiform precipitation maxima), except for the 22 August squall line for which the transition zone is not obvious. This figure is available in colour online at www.interscience.wiley.com/journal/qj

for the 6 August squall line). These features were also observed by Taupin and Gallaire (1998).

\subsection{Preliminary hypotheses}

In this section, we present different preliminary hypotheses that may explain the observed evolution of $\delta^{18} \mathrm{O}_{\mathrm{p}}$ and $d_{\mathrm{p}}$ along squall lines (Figure 4).

\subsubsection{Rain re-evaporation}

In previous studies, the evolution of $\delta^{18} \mathrm{O}_{\mathrm{p}}$ and $d_{\mathrm{p}}$ during storms has often been interpreted as the signature of rain re-evaporation (Taupin and Gallaire, 1998): as rain reevaporates, $\delta^{18} \mathrm{O}_{\mathrm{p}}$ increases (since the heavier isotopes concentrate in the condensed phase) and $d_{\mathrm{p}}$ decreases (since HDO diffuses faster than $\mathrm{H}_{2}^{18} \mathrm{O}$ out of the drop boundary layer). Re-evaporation is stronger where rainfall is weaker and relative humidity $(\mathrm{RH})$ is lower: at the start, in the transition zone and at the end of the rainfall. This could explain the $\mathrm{W}$ shape of $\delta^{18} \mathrm{O}_{\mathrm{p}}$. Reevaporation is also higher in the stratiform than in the convective zone (Zahiri, 2007), which could explain the decrease of $d$ in the stratiform zone. At the start and at the end of the 6 August squall line, the opposite evolution of $\delta^{18} \mathrm{O}_{\mathrm{p}}$ and $d_{\mathrm{p}}$ further supports the role of rain re-evaporation. However, re-evaporation alone would make $\delta^{18} \mathrm{O}_{\mathrm{p}}$ and $d_{\mathrm{p}}$ vary in opposite directions all along the squall line, in contradiction with the common evolution of $\delta^{18} \mathrm{O}_{\mathrm{p}}$ and $d_{\mathrm{p}}$ observed on 11,18 and 22 August (Figure 2). Moreover, the evolution of $\delta \mathrm{D}_{\mathrm{p}}$ and $\delta^{18} \mathrm{O}_{\mathrm{p}}$ in the $\delta \mathrm{D}$ versus $\delta^{18} \mathrm{O}$ diagram (Figure 3) does not follow the classical evaporation line with slope

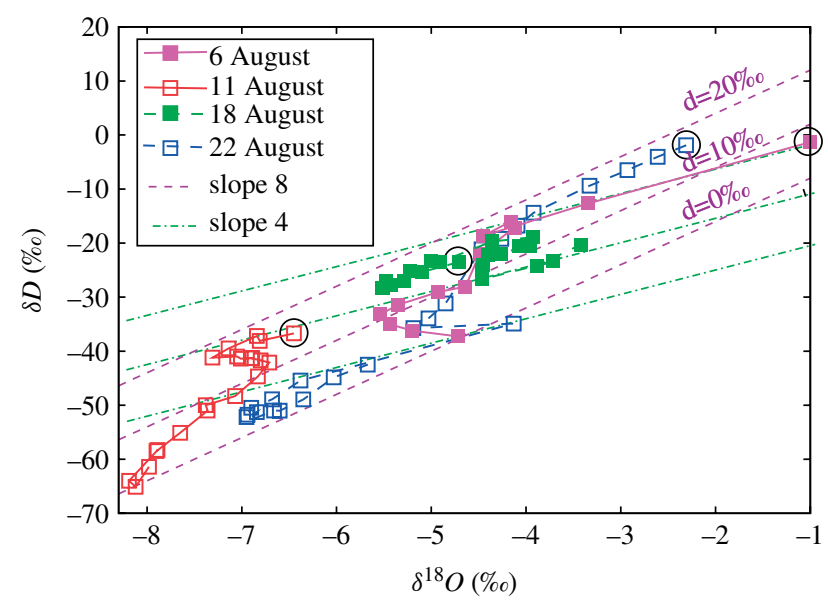

Figure 3. Evolution of $\delta \mathrm{D}$ versus $\delta^{18} \mathrm{O}$ of the precipitation for the four squall lines sampled. The first sample is highlighted with a black circle. Lines of slope 8 and 4 are also shown. Traditionally, condensation processes at equilibrium are assumed to follow a line of slope 8 and evaporation processes with kinetic fractionation a line of slope about 4 (Dansgaard, 1964). This figure is available in colour online at www.interscience.wiley.com/journal/qj

of the order of 4 or 5 expected from the effect of evaporation (Dansgaard, 1964). Therefore, this suggests that in addition to rain re-evaporation other processes are likely to be involved. We hypothesize in the following a series of processes that might explain the observed evolution (Figure 4).

\subsubsection{Condensation height}

The evolution of the precipitation composition might be related to that of the condensate that forms the 


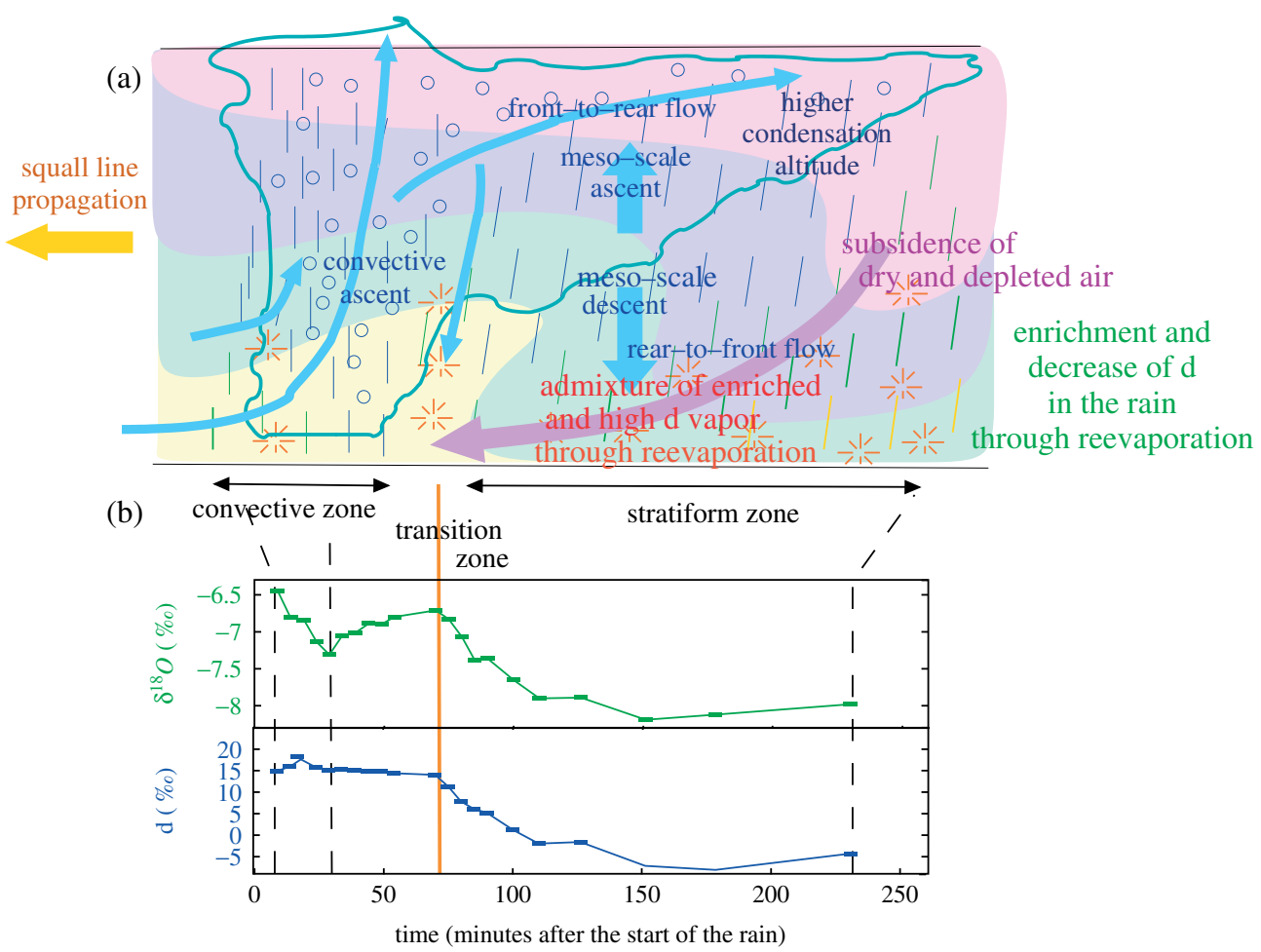

Figure 4. (a) Conceptual scheme illustrating the different mechanisms controlling the isotopic evolution along squall lines: condensation altitude, modification of the rain and low-level vapour by rain re-evaporation and diffusive exchanges and subsidence of depleted air. See section 2.3 for more details. (b) Evolution of $\delta^{18} \mathrm{O}$ and $d$-excess for the 11 August squall line. This figure is available in colour online at www.interscience.wiley.com/journal/qj

precipitation. The condensate is all the more depleted as it condenses higher in altitude, since the vapour is more strongly depleted by previous condensation at higher altitude due to the lower temperature (Celle-Janton et al., 2004; Gonfiantini et al., 2001). We expect the condensate to form higher in altitude in the stratiform zone than in the convective zone, since the mesoscale updraught in the stratiform zone is restricted to above the $0{ }^{\circ} \mathrm{C}$ isotherm approximately (Houze, 1977; Caniaux et al., 1994), whereas the convective updraughts extend throughout the troposphere. This could explain why $\delta^{18} \mathrm{O}_{\mathrm{p}}$ is usually lower in the stratiform zone than in the convective zone.

\subsubsection{Re-equilibration of raindrops with vapour}

As rain falls, it partially re-equilibrates isotopically with the surrounding vapour through diffusive exchange. This process is all the more efficient as $\mathrm{RH}$ is high (Stewart, 1975). Through this process, variations in the composition of the low-level vapour can be transmitted to the precipitation. The following two points are possible reasons for such variations in the low-level vapour composition.

\subsubsection{Mesoscale subsidence}

Owing to fractionation during condensation, vapour is more depleted as altitude increases. Therefore, a subsiding vapour is all the more depleted as it originates from higher in altitude. In squall lines, the mesoscale downdraught, combined with the rear-to-front flow, advects depleted vapour down to low levels under the stratiform zone. Re-equilibration of the rain with more depleted vapour might explain the lower $\delta^{18} \mathrm{O}_{\mathrm{p}}$ in the stratiform zone observed in most squall lines.

Through this process, the $\delta^{18} \mathrm{O}_{\mathrm{p}}$ should decrease more strongly after the transition zone in squall lines for which the mesoscale subsidence at the rear is strongest. To verify this hypothesis, we estimate qualitatively the strength of the subsidence by analyzing profiles of equivalent potential temperature $\left(\theta_{\mathrm{e}}\right)$ before and after the systems (Figure 1(c)): since $\theta_{\mathrm{e}}$ is minimum in the mid-troposphere before the arrival of the systems, a strong decrease of $\theta_{\mathrm{e}}$ in the lower troposphere suggests a strong subsidence (Zipser, 1977; Chalon et al., 1988). The 11 August squall line, which features a strong $\delta^{18} \mathrm{O}_{\mathrm{p}}$ decrease by $1.5 \%$ o from the transition zone to the minimum in the stratiform zone, also exhibits a strong $\theta_{\mathrm{e}}$ decrease extending up to $700 \mathrm{hPa}$. Conversely, the 18 August squall line, featuring a weak $\delta^{18} \mathrm{O}_{\mathrm{p}}$ decrease of only $0.4 \%$, exhibits a weaker $\theta_{\mathrm{e}}$ decrease restricted to below $800 \mathrm{hPa}$. The 6 August squall line is intermediate, with a $\delta^{18} \mathrm{O}_{\mathrm{p}}$ decrease by $1.4 \%$ and a $\theta_{\mathrm{e}}$ decrease extending up to $700 \mathrm{hPa}$ but weaker than that for 11 August. This comparison between the squall lines suggests that the subsidence effect on $\delta^{18} \mathrm{O}_{\mathrm{p}}$ could be substantial.

In addition, low RH at low levels associated with subsidence leads to lower $d_{\mathrm{p}}$ through rain re-evaporation. This could explain the parallel decrease of $\delta^{18} \mathrm{O}_{\mathrm{p}}$ and $d_{\mathrm{p}}$ observed after the transition zones. 


\subsubsection{Vapour modification through interaction with rain}

As raindrops re-evaporate or re-equilibrate isotopically with the vapour, the composition of the latter is modified. In squall lines, as low-level air flows from the rear to the front, it is exposed to rain re-evaporation and becomes more and more affected by diffusive exchanges and rain re-evaporation.

For strong rates of rain re-evaporation, the vapour resulting from rain re-evaporation is richer than the vapour at low levels, since its composition tends towards that of the rain when the re-evaporation is close to total. As an idealized example, using the module of isotopic fractionation during rain re-evaporation of Bony et al. (2008), we calculate that at $70 \%$ relative humidity the re-evaporation of a droplet of $\delta^{18} \mathrm{O}=-15 \%$ into a vapour of $\delta^{18} \mathrm{O}=-20 \%$ (respectively $-25 \%$ ) enriches the vapour if the re-evaporated fraction exceeds $70 \%$ (respectively 40\%). The re-evaporated fraction above which the vapour becomes enriched by evaporation is all the lower when the relative humidity is high and as the vapour becomes more depleted compared with the rain.

For low evaporation rates, in contrast, diffusive exchanges dominate over rain re-evaporation. In these conditions, the vapour might become more and more depleted by interaction with the rain (Gedzelman et al., 2003; Lee and Fung, 2008).

Zahiri (2007) calculated re-evaporation rates of $40-70 \%$ in the stratiform regions of Sahelian squall lines, suggesting that rain re-evaporation rather enriches the vapour in squall lines, in particular in stratiform zones.

In addition, the vapour from the rain re-evaporation has a higher $d$, since HDO diffuses faster than $\mathrm{H}_{2}^{18} \mathrm{O}$. Therefore, $\delta^{18} \mathrm{O}$ and $d$ in the vapour both increase as the air moves frontwards and is humidified by rain re-evaporation. In turn, the composition of the vapour affects the composition of the subsequent rain by isotopic equilibration (section 2.3.3). This would explain the simultaneous decrease of $\delta^{18} \mathrm{O}_{\mathrm{p}}$ and $d_{\mathrm{p}}$ rearwards along the stratiform zone after the transition zone, which is particularly visible on 11 and 22 August.

In the next section, we evaluate the relative contributions of these different processes in $2 \mathrm{D}$ simulations of the 11 August squall line.

\section{Detailed analysis of the 11 August 2006 squall line using a 2D model}

The restitution of the 3D wind field by Chong (2009) for the 11 August 2006 squall line, combined with a simple 2D model, offers a unique opportunity to evaluate the contribution of the aforementioned hypotheses. The 2D model allows us to simulate both microphysical and isotopic properties of the squall line. Although this model does not accurately simulate the observed isotopic evolution, given its simplicity (incorporating isotopes in a Cloud-Resolving Model (CRM) might be necessary for a more accurate prediction), we use it to investigate the processes controlling the isotopic composition of precipitation.

\subsection{Model description}

\subsubsection{Model physics, boundary conditions and numerical solution}

The model represents the transport and microphysics in a 2D (altitude-longitude) framework and we assume that the squall line is stationary. The model is inspired by the microphysical retrieval technique of Hauser et al. (1988), though simplified. The water vapour, cloud water and rain are advected in the $2 \mathrm{D}$ domain by $2 \mathrm{D}$ winds using an upstream advection scheme. Vapour condenses as soon as it reaches saturation. Microphysical processes are parametrized by the Kessler scheme (Kessler, 1969) using the same parameters as Hauser et al. (1988). The model also includes a representation of diffusion to ensure numerical stability.

West and east boundary conditions for $\mathrm{RH}$ are the $30 \mathrm{~min}$ averaged ARM profiles before and after the squall line (0100 UTC and 0900 UTC respectively) below $10 \mathrm{~km}$ and National Centers for Environmental Prediction (NCEP) profiles at 0600 UTC above this altitude. Temperature and pressure are assumed to be horizontally homogeneous and are taken from the ARM profiles at 0100 UTC below $10 \mathrm{~km}$ and from the reanalyses at 0600 UTC above $10 \mathrm{~km}$. Our results are not significantly sensitive to the representation of horizontal temperature perturbations (section 3.4). We neglect air and water fluxes throughout the bottom and top boundaries, but a sensitivity test to the addition of surface evaporation is presented in section 3.4.

In contrast to Hauser et al. (1988), we here calculate the stationary solution by temporal integration, because it facilitates the subsequent implementation of water isotopes. The advection, diffusion and microphysical processes are evaluated every $30 \mathrm{~s}$ until reaching a steady state, after about $15 \mathrm{~h}$. The model is initialized with the profiles of the west boundary conditions.

\subsubsection{Wind fields}

The 3D winds were retrieved following the procedure described in Chong (2009), using a squall-line propagation speed of $13.7 \mathrm{~m} / \mathrm{s}$. The wind field is highly variable in the along-line dimension, consistently with the high spatial and temporal variability pointed out by Lafore et al. (1988). We force the advection scheme with 2D winds obtained by averaging the $3 \mathrm{D}$ winds in the alongline (south-north) direction over different domains (Figure 5). Missing values are filled using a Cressman interpolation scheme as in Hauser et al. (1988). Winds are slightly modified so that they respect the conservation of air mass given the 2D framework and the prescribed temperature and pressure profiles. The along-line wind component is neglected. Such 2D winds are represented in Figure 6(a) and (b). Note that the domain is $122 \mathrm{~km}$ in the across-line direction and does not capture completely the rear of the squall line. However, extending the domain 


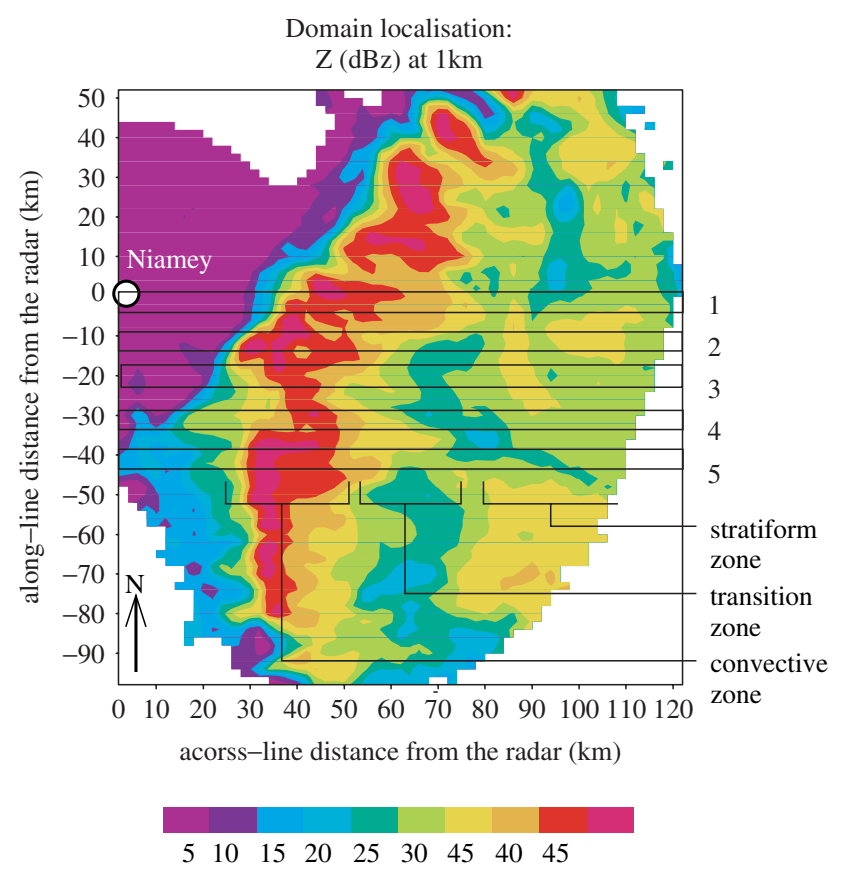

Figure 5. Horizontal reflectivity map from the MIT radar at $1 \mathrm{~km}$ on 11 August 2006 between 0241 and 0311 UTC, in the domain of the 3D wind retrieval extending over 120 and $150 \mathrm{~km}$ in the west-east and south-north directions, respectively. The five domains selected for our analysis in Figures 6 and 7 are indicated. The position of Niamey $(x=0 \mathrm{~km}, y=0 \mathrm{~km})$ is indicated by a white dot. This figure is available in colour online at www.interscience.wiley.com/journal/qj [Correction made here after initial online publication.]

by $100 \mathrm{~km}$ using additional wind profiles in the rear of the squall line has no influence on our results.

\subsubsection{Representation of isotopic processes}

Isotopic species are transported passively by advection and diffusion, but fractionation is introduced at each phase change. The implementation of fractionation during condensation, evaporation and diffusive exchanges is detailed in Bony et al. (2008). It is similar to that used in most isotopic general circulation models (Jouzel et al., 1991; Hoffmann et al., 1998; Noone and Simmonds, 2002b; Lee et al., 2007; Tindall et al., 2009) except for rain re-evaporation: we calculate explicitly the degree of equilibration between rain and vapour and take into account the concomitant evolution of both rain and vapour composition throughout the evaporation process (appendix A of Bony et al., 2008).

The isotopic boundary and initial conditions are Rayleigh distillation profiles, which represent the effect of previous condensation and precipitation:

$$
R_{\mathrm{v}}(z) \sim R_{\mathrm{v} 0}\left(\frac{q_{\mathrm{sat}}(z)}{q_{\mathrm{v} 0}}\right)^{\alpha-1},
$$

where $R_{\mathrm{V}}(z)$ is the profile of the isotopic ratio in the vapour, $R_{\mathrm{v} 0}$ and $q_{\mathrm{v} 0}$ are the isotopic ratio and the specific humidity at the lowest level $(0-500 \mathrm{~m}), q_{\text {sat }}(z)$ is the saturation specific humidity at the temperature of level $z$ and $\alpha$ is the effective fractionation (including kinetic fractionation) at the same temperature. We take $\delta^{18} \mathrm{O}_{\mathrm{v} 0}=-15 \%$ and $d_{\mathrm{v} 0}=10 \%$ o to yield $\delta^{18} \mathrm{O}_{\mathrm{p}}$ and $d_{\mathrm{p}}$ of the same order of magnitude as those observed (the evolution of $\delta^{18} \mathrm{O}_{\mathrm{p}}$ and $d_{\mathrm{p}}$ is insensitive to these values). Sensitivity to the Rayleigh assumption will be discussed in section 3.4.

\subsection{Model results}

Given the strong along-line variability in the wind field, we consider various cross-line transects of the squall line (Figure 5). Rather than trying to reproduce exactly the observed isotopic evolution, we explore the different dynamics based on a single squall line, as a 'proxy' for different squall lines. Figure 6 shows five of these simulations, representative of the variability range of the results. The goal is to extract the robust and consistent features among the different simulations, as well as exploring the along-line variability.

The simulated precipitation (Figure 6(e)) is of the same order of magnitude as in the observations (Figure 2), and with similar evolution: the model simulates a maximum corresponding to the convective zone and a secondary maximum corresponding to the stratiform zones. The simulated 2D fields of relative humidity (Figure 6(c)), cloud water content (Figure 6(d)), condensation, precipitation and evaporation rates (not shown) are consistent with fields retrieved by the unidimensional method of Chong (2009) for this same squall line. More generally, these fields are consistent in patterns and in magnitude with fields for other squall lines retrieved by the more sophisticated method of Hauser et al. (1988) or simulated by 3D models (Lafore et al., 1988; Caniaux et al., 1994). The physics of the squall line is thus reasonably well captured by the $2 \mathrm{D}$ model, and can be used to investigate isotopic controls.

The isotopic evolution of the precipitation is very sensitive to the squall-line dynamics: for the same microphysical model and the same squall line, along-line wind variations induce a strong variability in the shape of 

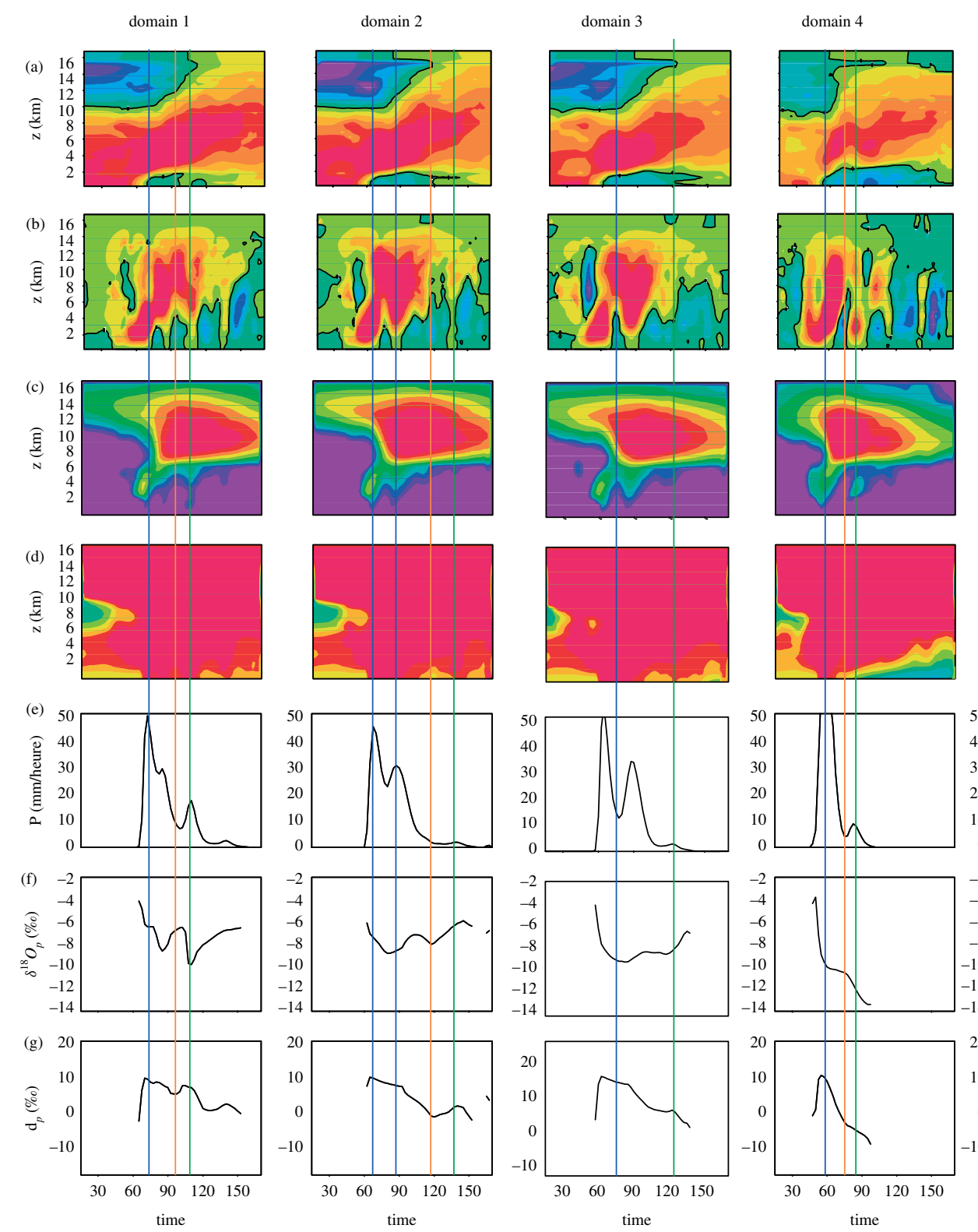

domain 5
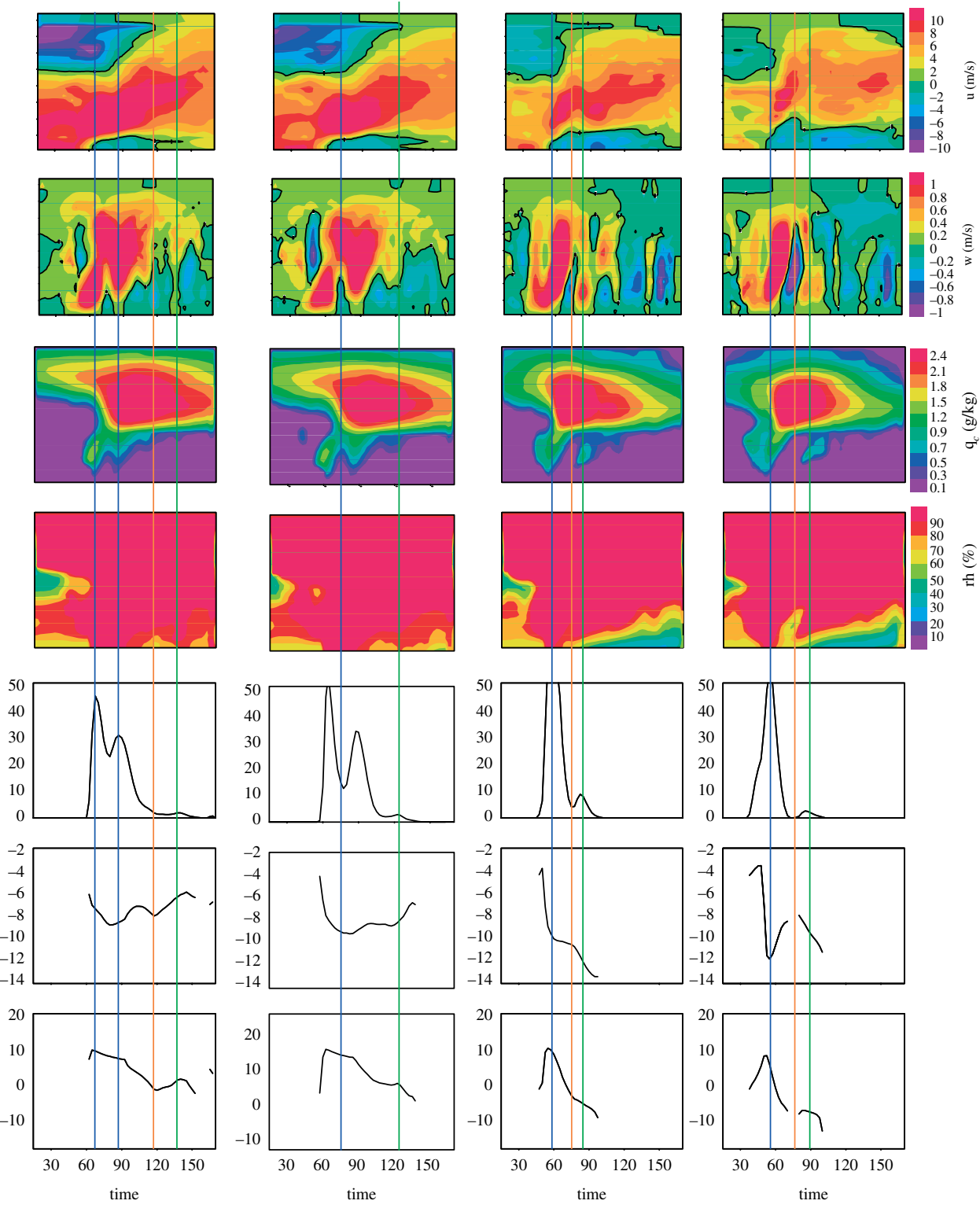

(minutes after passage over the radar)

Figure 6. Five examples of simulations along different across-line transects of the 11 August 2006 squall line. (a) and (b) Across-line and vertical wind components of the $2 \mathrm{D}$ wind field used to force the model; the zero isoline is highlighted. (c) Simulated condensate water content (both liquid and ice). (d) Simulated relative humidity. (e), (f) and (g) Simulated evolution of the precipitation rate, $\delta^{18} \mathrm{O}$ and $d$-excess. The different domains are shown in Figure 5. The vertical lines indicate the position of the convective cores (dashed/blue), transition zones (solid/orange) and stratiform precipitation maxima (dotted/green). This figure is available in colour online at www.interscience.wiley.com/journal/qj

the isotopic evolution, especially in $\delta^{18} \mathrm{O}_{\mathrm{p}}$ (Figure 6(f)). However, all simulations share the same robust features observed for the different squall lines (section 2.2), i.e. the W shape of the $\delta^{18} \mathrm{O}_{\mathrm{p}}$ evolution and the decrease of $d_{\mathrm{p}}$.

The different simulations also span the variability observed for the different squall-line samples: domain 2 , for example, features in addition to the $\mathrm{W}$ shape an increasing trend of $\delta^{18} \mathrm{O}$ of about $1 \%$ from the convective precipitation maximum to the stratiform precipitation maximum, as observed for the 18 August squall line. On the other hand, the other domains feature decreasing trends spanning from $1-4 \%$, in the range of the other observed squall lines. The $d_{\mathrm{p}}$ decrease in the first part of the stratiform zone is well reproduced in all simulations (Figure 6(g)). However, the re-increase of $d_{\mathrm{p}}$ at the end of the squall line is never simulated. Also, none of the simulations was able to reproduce the particular $d_{\mathrm{p}}$ pattern of August 18, suggesting that the dynamics or microphysics of this line were unique.

3.3. Processes controlling the isotopic composition in the model

Although the exact isotopic evolution of the 11 August squall line was not reproduced, the simulated isotopic features are consistent with the observations, and the simulated along-line isotopic variability is comparable with the variability observed among squall lines. We now 

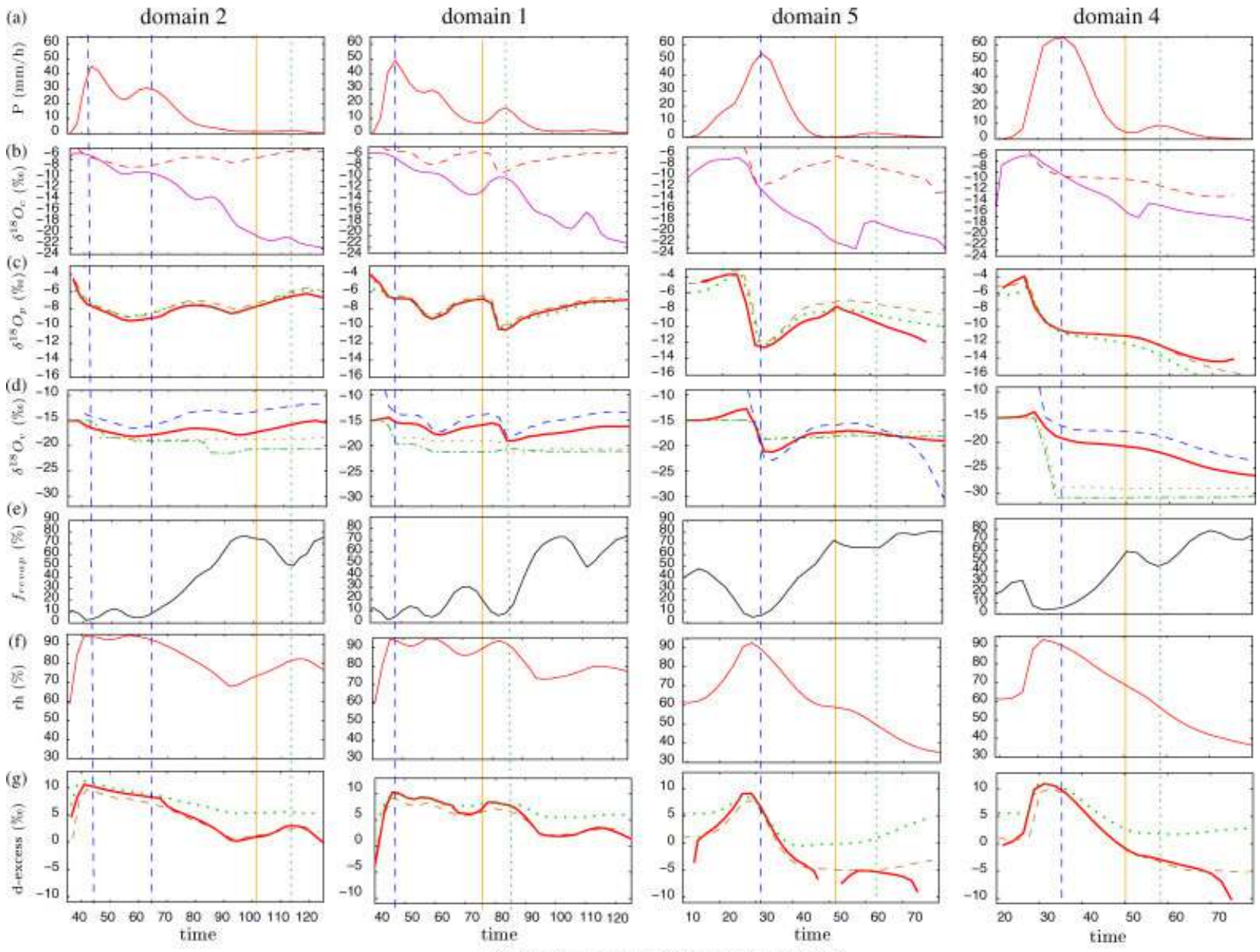

time (minutes after passage over the radar)

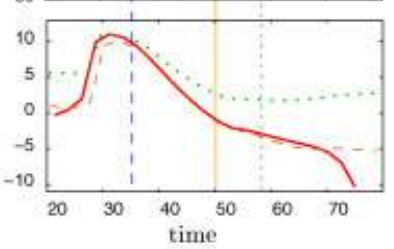

Figure 7. Evolution of some simulated characteristics illustrating what controls the isotopic evolution along the squall line in the model. (a) Precipitation rate. (b) $\delta^{18} \mathrm{O}$ of the condensate forming the precipitation (solid/purple). The $\delta^{18} \mathrm{O}$ of the precipitation is shown in dashed/red for comparison. (c) $\delta^{18} \mathrm{O}$ of the precipitation simulated by the 2D model (solid/red) and predicted by the simple re-evaporation equation (1) (dashed/brown). The liquid in equilibrium with the lowest-level vapour is shown in dotted/green. (d) $\delta^{18} \mathrm{O}$ of the vapour at the lowest level of the model: total vapour simulated by the model (thick solid/red), vapour originating from rain re-evaporation in the model (dashed/blue) and vapour advected from the different levels (dash-dotted/green). The vapour predicted by a Rayleigh distillation using the maximum altitude undergone, $\overline{z_{\max }}$, is shown in dotted/brown. (e) Fraction of the rain re-evaporated. (f) Relative humidity at the lowest level. (g) $d$-excess of the precipitation simulated by the $2 \mathrm{D}$ model (solid/red) and predicted by the simple re-evaporation equation (1) (dashed/brown). The liquid in equilibrium with the lowest-level vapour is shown in dotted/green. As in Figure 6, the vertical lines indicate the position of the convective cores (dashed/blue), transition zones (solid/orange) and stratiform precipitation maxima (dotted/green). This figure is available in colour online at www.interscience.wiley.com/journal/qj

use the model to explore what processes, among the ones described in section 2.3, control this isotopic evolution.

\subsubsection{Control of precipitation $\delta^{18} O$}

The evolution of $\delta^{18} \mathrm{O}_{\mathrm{p}}$ (Figure 7(c)) has no similarities with the evolution of the $\delta^{18} \mathrm{O}$ of the condensate from which the precipitation originates $\left(\delta^{18} \mathrm{O}_{\mathrm{c}}\right.$, i.e. vertically averaged $\delta^{18} \mathrm{O}$ of the condensate weighted by the rate of conversion to precipitation, Figure 7(b)). Variations in $\delta^{18} \mathrm{O}_{\mathrm{c}}$ thus do not yield any visible variations in $\delta^{18} \mathrm{O}_{\mathrm{p}}$, suggesting that processes controlling $\delta^{18} \mathrm{O}_{\mathrm{c}}$ (such as condensation height) have little influence on $\delta^{18} \mathrm{O}_{\mathrm{p}}$. On the contrary, $\delta^{18} \mathrm{O}_{\mathrm{p}}$ tightly follows the $\delta^{18} \mathrm{O}$ of the low-level vapour (between 0 and $500 \mathrm{~m}$, hereafter $\delta^{18} \mathrm{O}_{\mathrm{v}}$, Firue $7(\mathrm{~d})$ ), suggesting that the precipitation re-equilibrates isotopically as it falls, 'forgetting' its condensation history.
To check this hypothesis and to interpret the isotopic ratio in the precipitation, $R_{\mathrm{p}}$, simulated by the $2 \mathrm{D}$ model, we use a deliberately simple equation (Stewart, 1975):

$$
R_{\mathrm{p}}=R_{l 0} f_{\mathrm{r}}^{\beta}+\gamma R_{\mathrm{v}}\left(1-f_{\mathrm{r}}^{\beta}\right),
$$

where $R_{\mathrm{v}}$ is the simulated isotopic ratio in the lowestlevel vapour, $f_{\mathrm{r}}$ the simulated vertically integrated fraction of the rain that remains after re-evaporation (Figure 7(e)), $R_{l 0}$ the composition of the condensate that forms the precipitation and $\beta$ and $\gamma$ coefficients depending on low-level RH (defined by Stewart (1975) and recalled in appendix A of Bony et al. (2008)). This Equation (1) is a strong simplification of processes represented in the 2D model: the goal here is to reproduce the modelled results with as simple an equation as possible, to identify the dominant processes. Firstly, we assume that $R_{\mathrm{v}}$ varies little as evaporation proceeds, neglecting the 
feedback of re-evaporation on $R_{\mathrm{v}}$ (Stewart, 1975). Secondly, we assume that the composition of the condensate forming the precipitation is constant $\left(\delta^{18} \mathrm{O}_{\mathrm{c}}=-15 \%\right.$, corresponding to the average values in the simulations), so as to check that variations in $\delta^{18} \mathrm{O}_{\mathrm{c}}$ are not a dominant control on $\delta^{18} \mathrm{O}_{\mathrm{p}}$. Thirdly, we consider only the vertically integrated $f_{\mathrm{r}}$ and take $R_{\mathrm{v}}$ and $\mathrm{RH}$ at the lowest level only, whereas re-evaporation is treated at all vertical levels in the 2D model.

This equation is able to reproduce well the $\delta^{18} \mathrm{O}_{\mathrm{p}}$ evolution simulated by the 2D model (Figure 7(c)), showing that variations in the condensate composition have little influence on $\delta^{18} \mathrm{O}_{\mathrm{p}}$. Rather, rain re-evaporation and isotopic equilibration with the vapour are key controls of $\delta^{18} \mathrm{O}_{\mathrm{p}} \cdot \delta^{18} \mathrm{O}_{\mathrm{p}}$ is actually very close to isotopic equilibrium with the vapour (Figure 7(c)), in agreement with Lee and Fung (2008), who simulated a degree of rain-vapour equilibration above $70 \%$ over the Tropics. Therefore, understanding of $\delta^{18} \mathrm{O}_{\mathrm{p}}$ requires an understanding of what controls $\delta^{18} \mathrm{O}_{\mathrm{v}}$. This is discussed below.

\subsubsection{Control of vapour $\delta^{18} \mathrm{O}$}

The vapour at low levels in the 2D model is a mixture of vapour originating from rain re-evaporation and vapour advected from different levels. In section 2.3, we hypothesized that rain re-evaporation and subsidence could influence the low-level vapour composition. To evaluate these two hypotheses, we implemented a method to track the vapour origin in the $2 \mathrm{D}$ model, as detailed in appendix $\mathrm{A}$. This method allows us to estimate (1) the fraction of the vapour that originates from rain re-evaporation or advection from different levels, and (2) the isotopic composition of air parcels originating from rain re-evaporation $\left(\delta^{18} \mathrm{O}_{\mathrm{e}}\right)$ or advection by the dynamics $\left(\delta^{18} \mathrm{O}_{\mathrm{dyn}}\right)$.

Since the two sources of vapour are rain evaporation and advection by the dynamics (and more particularly by subsidence), the evolution of $\delta^{18} \mathrm{O}_{\mathrm{v}}$ is intermediate between the evolution of $\delta^{18} \mathrm{O}_{\mathrm{e}}$ and $\delta^{18} \mathrm{O}_{\text {dyn }}$ (Figure 7(d)). For domain 4 , the $11 \%$ decrease in $\delta^{18} \mathrm{O}_{\mathrm{v}}$ along the line is driven by the $16 \%$ decrease of $\delta^{18} \mathrm{O}_{\text {dyn }}$. Since any departure of $\delta^{18} \mathrm{O}_{\mathrm{dyn}}$ from the boundary value of $-15 \%$ is entirely due to the subsidence, this demonstrates the impact of subsidence on $\delta^{18} \mathrm{O}_{\mathrm{v}}$. More generally, the role of the dynamics is dominant in all the domains in which $\delta^{18} \mathrm{O}_{\mathrm{p}}$ features a strong depletion (more than 5\%o) from the convective to the stratiform zone (not shown). For the other domains, the evolution of $\delta^{18} \mathrm{O}_{\mathrm{v}}$ follows more closely the evolution of $\delta^{18} \mathrm{O}_{\mathrm{e}}$ and is thus primarily affected by rain re-evaporation. For example, in domain 1 the $2 \%$ variations in $\delta^{18} \mathrm{O}_{\mathrm{v}}$ around the transition zone are due to the $3 \%$ variation in $\delta^{18} \mathrm{O}_{\mathrm{e}}$.

In the following paragraphs, we detail what controls the evolution of $\delta^{18} \mathrm{O}_{\text {dyn }}$ and $\delta^{18} \mathrm{O}_{\mathrm{e}}$.

The method to track the vapour origin in the $2 \mathrm{D}$ model allows us to estimate the average maximum altitude reached by low-level parcels during their transport through the squall line (appendix A). The maximum altitude $\overline{z_{\max }}$ that parcels have undergone is equivalent to the minimum temperature encountered (since we neglect horizontal temperature perturbations) and thus represents the maximum depletion undergone by the parcels as they condense during their ascent. The $\overline{z_{\max }}$ altitude thus controls, at first order, the composition of the subsiding vapour, in an analogous way to the minimum saturation temperature encountered controlling the relative humidity of subsiding vapour (Pierrehumbert and Roca, 1998). Indeed, as shown in Figure 7(d) (dashed), a simple Rayleigh distillation predicts well the composition of the vapour advected by the dynamics $\delta^{18} \mathrm{O}_{\text {dyn }}$ :

$$
R_{\mathrm{dyn}} \sim R_{\mathrm{v} 0}\left(\frac{q_{\mathrm{sat}}\left(\overline{z_{\mathrm{max}}}\right)}{q_{\mathrm{v} 0}}\right)^{\alpha-1}
$$

where $R_{\mathrm{v} 0}$ and $q_{\mathrm{v} 0}$ are the composition and specific humidity of the boundary vapour at low levels, and $\alpha$ the effective isotopic fractionation. Note that this equation neglects the effect of cloud and rain re-evaporation on the vertical isotopic profiles.

Due to the squall-line dynamics (mesoscale downdraught and rear-to-front flow), $\overline{z_{\max }}$ increases from the convective to the stratiform zone. For domain $4, \overline{z_{\max }}$ increases from $0 \mathrm{~km}$ at the beginning of the line (no subsidence) to $2.5 \mathrm{~km}$ in the stratiform zone, leading to the strong decrease of $\delta^{18} \mathrm{O}_{\text {dyn }}$ (from -15 to $-31 \%$ ) and thus that of $\delta^{18} \mathrm{O}_{\mathrm{v}}\left(-15\right.$ to $-22 \%$ ) and $\delta^{18} \mathrm{O}_{\mathrm{p}}(-4$ to $-12 \%$ ). This confirms the importance of mesoscale subsidence in the control of isotopic composition of the vapour and precipitation along squall lines.

On the other hand, the composition of the reevaporated vapour $\left(\delta^{18} \mathrm{O}_{\mathrm{e}}\right)$ follows the evolution of the

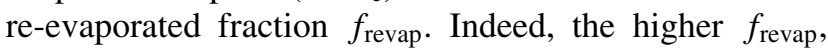
the more enriched the vapour from rain re-evaporation. As expected from section 2.3.5, the rain re-evaporation is generally more enriched than the vapour, by $1-4 \%$. In addition to the effect of $f_{\text {revap, }}$, the evolution of $\delta^{18} \mathrm{O}_{\mathrm{e}}$ is modulated by how the squall-line dynamics transports the re-evaporated vapour.

To conclude regarding the control of $\delta^{18} \mathrm{O}_{\mathrm{p}}$ in the $2 \mathrm{D}$ model, $\delta^{18} \mathrm{O}$ in vapour and thus in precipitation is controlled by two processes: (1) mesoscale subsidence of depleted air and (2) admixture of vapour arising from the re-evaporation of the falling rain and transported by the squall-line dynamics. Note that the controls on low-level RH are very similar: subsidence brings dry air downwards, while evaporation moistens this air as it moves frontwards under the stratiform region.

\subsubsection{Control of precipitation deuterium excess}

The evolution of deuterium excess in precipitation $\left(d_{\mathrm{p}}\right)$ follows very tightly that of low-level $(0-500 \mathrm{~m}) \mathrm{RH}$ (Figure 7(f) and $(\mathrm{g})) . d_{\mathrm{p}}$ thus seems to be mainly controlled by $\mathrm{RH}$ during rain re-evaporation: the lower the $\mathrm{RH}$, the more dominant kinetic fractionation is relative to equilibrium fractionation, and thus the lower $d_{\mathrm{p}}$. The good prediction of the $d_{\mathrm{p}}$ evolution by Equation (1) (Figure $7(\mathrm{~g})$; dashed), which includes the effect of 
low-level RH, confirms that re-evaporation is the key control on $d_{\mathrm{p}}$.

The linear correlation coefficient between the evolution of $d_{\mathrm{p}}$ and low-level $\mathrm{RH}$ (where the precipitation is significant: $>0.5 \mathrm{~mm} / \mathrm{h}$ ) varies from $0.90-0.97$ for the different domains (not shown). The relationship $d_{\mathrm{p}}-\mathrm{RH}$ is robust, with a slope ranging from $0.30-0.37 \%$ o $/ \%$. In our model, $d_{\mathrm{p}}$ is thus an excellent indicator of the RH. However, this $d_{\mathrm{p}}-\mathrm{RH}$ relationship cannot be checked with observations, because although we do have $\mathrm{RH}$ measurements at the surface along the squall line sampled, the RH at the surface does not accurately reflect the low-level RH that affects the isotopic composition of the rain.

\subsection{Sensitivity tests to dynamics, microphysics and isotopes}

We discuss below the sensitivity of our results to different assumptions made in our model.

\subsubsection{Horizontal temperature perturbations}

We neglect horizontal perturbations in the 2D model, whereas Hauser et al. (1988) evaluated temperature perturbations of the order of $-4 \mathrm{~K}$ in the rear-to-front flow. Decreasing the temperature by about $4 \mathrm{~K}$ in the rearto-front flow slightly increases the relative humidity by $10 \%$ locally, increases $\delta^{18} \mathrm{O}_{\mathrm{p}}$ by $2 \%$ and $d_{\mathrm{p}}$ by about $5 \%$. However, it does not qualitatively change the isotopic evolution.

\subsubsection{Rayleigh assumption}

In nature, isotopic profiles in the upper troposphere are usually more enriched than predicted by a Rayleigh distillation, due to convective detrainment (Moyer et al., 1996; Dessler and Sherwood, 2003; Webster and Heymsfield, 2003; Bony et al., 2008). Here we consider Rayleigh distillation as west and east boundary conditions. However, modifying the isotopic profile at upper levels does not affect our results much: when assuming that $50 \%$ of the condensate formed during the Rayleigh distillation is detrained rather than instantaneously precipitated (leading to an enrichment of up to $70 \%$ at $16 \mathrm{~km}), \delta^{18} \mathrm{O}$ only increases by $1-2 \%$ in the stratiform zone.

\subsubsection{Microphysics}

We also performed sensitivity tests to microphysics (not shown). Little isotopic sensitivity was found to Kessler parameter variations, even though the precipitation evolution was sometimes deeply distorted. This confirms that the dynamic control dominates. The isotopic parameter $\phi$ (controlling the intensity of kinetic effects during evaporation, see appendix A of Bony et al., 2008) was the only isotopic parameter to have a significant sensitivity. When $\phi=0$ (strong kinetic effects), $\delta^{18} \mathrm{O}_{\mathrm{p}}$ is increased by $3 \%$ o and $d_{\mathrm{p}}$ is decreased by $10 \% \mathrm{o}$ at the start and the rear of the squall line, where evaporation is the strongest and the atmosphere the driest. This confirms that the details of the parametrization of the isotopic behaviour during re-evaporation are crucial in dry conditions. However, this parameter had little influence on the evolution in the convective and stratiform zones.

The drop-size distribution has been shown to influence the isotopic evolution of the rain as it re-evaporates (Lee and Fung, 2008). However, explicitly taking into account the effect of the drop-size distribution, rather than assuming homogeneous drop sizes, has little influence on our 2D model results. In our model, the rain dropsize distribution influences the re-evaporated fraction $f_{\text {revap }}$, since the smallest drops would re-evaporate totally whereas the largest drops conserve most of their mass. In a sensitivity experiment, the drop-size distribution was determined by the Kessler microphysics scheme (Kessler, 1969) and isotopic calculations were performed in each of 40 size bins. The results were virtually unchanged, except in extremely dry re-evaporation conditions. For example, for $f_{\text {revap }}=80 \%$ and $h=50 \%, \delta^{18} \mathrm{O}_{\mathrm{p}}$ in the squall-line precipitation was decreased by $2 \%$ and $d_{\mathrm{p}}$ was increased by $1 \%$ when taking into account the drop-size distribution.

\subsubsection{Surface evaporation}

None of our simulations is able to reproduce the $d_{\mathrm{p}}$ increase observed at the end of most squall lines. A possible interpretation might be the re-evaporation of the water accumulated on the soil, neglected in our model, which would increase $d_{\mathrm{v}}$ and thus $d_{\mathrm{p}}$ by re-equilibration of raindrops with the vapour. To check this hypothesis, we performed simulations in which we added surface evaporation, calculated by a simple Penman-like equation (appendix B). A large uncertainty in this calculation is the net radiation minus soil heat flux, $R_{\mathrm{n}}-G$, under the heavy cloud cover of a squall line. Therefore, we performed tests with different values for $R_{\mathrm{n}}-G$. As justified in appendix $\mathrm{B}$, we take $R_{\mathrm{n}}-G=150 \mathrm{~W} / \mathrm{m}^{2}$ as an upper bound for a midday squall line, and $R_{\mathrm{n}}-G=$ $0 \mathrm{~W} / \mathrm{m}^{2}$ for a night-time squall line.

For $R_{\mathrm{n}}-G=150 \mathrm{~W} / \mathrm{m}^{2}$ (midday), the resulting evaporation reaches maxima of $6 \mathrm{~mm} /$ day in the stratiform zone for domains with very dry air in the stratiform zone (domains 4,5) and $3 \mathrm{~mm} /$ day for domains with wetter air (domains 1, 2). For $R_{\mathrm{n}}-G=0 \mathrm{~W} / \mathrm{m}^{2}$ (night), the evaporation peaks at $2 \mathrm{~mm} /$ day. The moistening effect of surface evaporation is very small. It is maximum for squall lines with dry stratiform regions (domains 4 and 5) at midday, but the relative humidity is increased by only $4-6 \%$. This is because the surface evaporation flux under the squall line is much smaller than the vapour flux from advection, due to the small spatial scale of the squall line.

The effect on $\delta^{18} \mathrm{O}_{\mathrm{p}}$ is negligible (always lower than $1 \%$ o). The $d$ of the evaporation flux, $d_{\text {sfc }}$, is highly sensitive to the kinetic fractionation formulation. Taking Mathieu and Bariac (1996)'s formulation for a saturated soil, $d_{\mathrm{sfc}}$ is $140 \%$ o higher than $d_{\mathrm{v}}$. The $d_{\mathrm{v}}$ is increased by $7 \%$ at midday in dry stratiform zones, but only by $2-3 \%$ o in wetter stratiform zones at midday and by less than $1 \%$ o during the night. This effect of surface evaporation on 
$d_{\mathrm{v}}$ is almost totally transmitted to $d_{\mathrm{p}}$. The transmission of the $d_{\mathrm{v}}$ anomaly to $d_{\mathrm{p}}$ is by rain re-equilibration with the vapour, since the vapour from surface evaporation is only confined to low levels due to the subsidence in the stratiform zone.

Therefore, the effect of surface evaporation on $d_{\mathrm{p}}$ may be significant for dry stratiform zones at midday. However, the increase of $d_{\mathrm{p}}$ at the end of the 22 August stratiform zone by $15 \%$ presumably does not result from surface evaporation only. Since the 11 August squall line occurred mainly during night-time, the $5 \%$ o increase in $d_{\mathrm{p}}$ is also not attributable to surface evaporation only.

\section{Summary and conclusions}

\subsection{Summary}

This paper presents the evolution of precipitation $\delta^{18} \mathrm{O}$ and $d$ along different squall lines observed in the Sahel during the AMMA campaign. Despite a large variability in the isotopic evolution among the different squall lines, some robust features appear, such as the $\mathrm{W}$ shape of $\delta^{18} \mathrm{O}_{\mathrm{p}}$ and the decrease of $d_{\mathrm{p}}$ in the stratiform region. Several processes may a priori contribute to such evolution, such as the condensation altitude, modifications of the rain composition as it re-evaporates during its fall and variations of the composition of the vapour with which the rain re-equilibrates, due either to subsidence or to interaction with the falling rain.

To test these hypotheses and explore the relative contributions of the dynamics and the microphysics of the squall line to the evolution of the isotopic composition of the rain, a simple 2D model of transport and microphysics forced by observed wind fields was developed. The 2D model run on various along-line transects is able to simulate isotopic evolutions consistent with observations and with a comparable amplitude of variability. In the model, $\delta^{18} \mathrm{O}_{\mathrm{p}}$ is mainly controlled by (1) the squall-line dynamics: mesoscale subsidence in the stratiform portion of the system advects depleted water vapour downward and the horizontal flows redistribute this vapour in the low levels, and (2) the re-evaporation of the rain, which moistens the low-level vapour and affects its composition.

\subsection{What can we learn from water isotopes about squall lines?}

The robust features of the evolution of $\delta^{18} \mathrm{O}_{\mathrm{p}}$ and $d_{\mathrm{p}}$ along squall lines demonstrate the strong influence of convective processes on the isotopic composition. $\delta^{18} \mathrm{O}_{\mathrm{p}}$ is particularly sensitive to both the squall-line dynamics and rain re-evaporation processes, and could thus provide some integrated information about the dynamics within the squall line (e.g., the vertical Lagrangian excursions of the air parcels). On the other hand, $d_{\mathrm{p}}$ is a more direct tracer of rain re-evaporation, and the $2 \mathrm{D}$ model suggests a very robust relationship between $d_{\mathrm{p}}$ and relative humidity of the air at low levels. If incorporated into a CRM, stable water isotopes could thus serve as a tool to validate the squall-line dynamics or the recycling of water through rain re-evaporation.

4.3. Implication for the control of the composition of tropical precipitation on larger scales

One of the goals of this study was to better understand the effect of convective processes on the composition of tropical precipitation. Risi et al. (2008a), in very different conditions (a single-column model over the ocean), suggested that the effect of condensation processes was relatively small compared with the effect of two other processes, namely (1) rain re-evaporation, enriching the raindrops as they fall and (2) mesoscale subsidence of higher altitude vapour, depleting the low-level vapour. The minimal effect of condensation processes is confirmed in this study: as the raindrops re-equilibrate with the low-level vapour, they totally 'forget' the effect of condensation processes, in agreement with Lee and Fung (2008). This study also confirms the strong effects of rain re-evaporation (especially on $d_{\mathrm{p}}$ ) and mesoscale subsidence (particularly on $\delta^{18} \mathrm{O}_{\mathrm{p}}$ ). The primary control of the isotopic composition of tropical precipitation by rain re-evaporation and mesoscale subsidence or convectivescale downdraughts thus seems to occur over a wide range of conditions and time and space scales.

In addition, the $2 \mathrm{D}$ model suggests that rain reevaporation has a significant role on the vapour $\delta^{18} \mathrm{O}$. Using global satellite data, Worden et al. (2007) had already cited rain re-evaporation as a control for vapour $\delta^{18} \mathrm{O}$. However, they hypothesized that rain reevaporation depletes the vapour, whereas our study suggests that rain re-evaporation tends to enrich the lowlevel vapour. The difference is due to (1) the strong re-evaporation of the rain in our case, which invalidates the approximation made in Worden et al. (2007) that the composition of the evaporation does not depend on the re-evaporated fraction of the rain, and (2) the strong depletion of the low-level vapour by mesoscale subsidence in our case (neglected in Worden et al., 2007). Based on our results, we would therefore suggest that the strong depletion of water vapour observed by Worden et al. (2007) is related to unsaturated downdraughts and mesoscale subsidence associated with convection (Zipser, 1977).

The large temporal $\delta^{18} \mathrm{O}_{\mathrm{p}}$ variations along squall lines (up to 5\% in the 6 and 22 August squall lines) are almost the same order of magnitude as the intraseasonal variations of the event-averaged isotopic composition after the onset, with $\delta^{18} \mathrm{O}_{\mathrm{p}}$ ranging from $-1.5 \%$ to $-7.5 \%$ o (Risi et al., 2008b). This raises the question of the role of individual squall-line dynamics in controlling the $\delta^{18} \mathrm{O}_{\mathrm{p}}$ at the intraseasonal scale. However, no correlation was found between $\delta^{18} \mathrm{O}_{\mathrm{p}}$ and the rainfall amount or type of system at the scale of individual events: $\delta^{18} \mathrm{O}_{\mathrm{p}}$ instead seems to record a large-scale, low-frequency signal of intraseasonal variability. Using the $2 \mathrm{D}$ model, we investigated the effect of $\delta^{18} \mathrm{O}_{\mathrm{p}}$ perturbations of the vapour at different levels on the event-averaged precipitation. A 
$\delta^{18} \mathrm{O}$ perturbation in the monsoon flow layer $(0-3 \mathrm{~km})$ is almost totally $(85 \%)$ imprinted in the averaged $\delta^{18} \mathrm{O}_{\mathrm{p}}$. In contrast, perturbations at the level of the African Easterly Jet $(3-6 \mathrm{~km})$, which are potentially larger (Bony et al., 2008), are only partially (15\%) imprinted in the averaged $\delta^{18} \mathrm{O}$. This is because $\delta^{18} \mathrm{O}_{\mathrm{p}}$ is mainly controlled by the $\delta^{18} \mathrm{O}$ of low level vapour, and the stratiform zone, affected by $\delta^{18} \mathrm{O}$ perturbations at higher levels through subsidence, contributes little to the total precipitation. We hypothesize that $\delta^{18} \mathrm{O}_{\mathrm{p}}$ temporally integrates the convective activity because convection strongly affects the $\delta^{18} \mathrm{O}$ of the boundary-layer vapour, which in turn then controls the $\delta^{18} \mathrm{O}_{\mathrm{p}}$ of the following rain event. More work is needed to understand the relative impact on the isotopic composition of tropical precipitation of (1) the dynamics and convective processes in individual convective systems and (2) the impact of larger-scale processes imprinted in the large-scale vapour feeding the systems at different levels.

\subsection{Perspectives}

We are aware of the limits of the 2D model, due to the simple microphysics parametrization, assuming that the squall line is stationary and neglecting the along-line wind component. In particular, Lafore et al. (1988) and Redelsprger and Lafore, 1987) have shown that alongline variability in the $3 \mathrm{D}$ wind field and transient flows substantially contributes to the moisture transport. We are not able to simulate the observed evolution accurately, although all observed evolution is in the range of the various simulations performed. Incorporating stable water isotopes into a CRM could be a next step. The coupling of such a model with a detailed soil model would also enable a more quantitative estimate of the effect of surface evaporation on the isotopic composition at the end of squall lines.

In addition, measuring the isotopic composition simultaneously in the precipitation and in the vapour would yield invaluable information about what controls $\delta^{18} \mathrm{O}_{\mathrm{p}}$ and $d_{\mathrm{p}}$ : it would allow us to evaluate the degree of re-equilibration of raindrops with the low-level vapour, which might depend on drop size (Lee and Fung, 2008). Similar evolution in the precipitation and vapour would confirm good re-equilibration between the rain and vapour and would support the idea that the dynamics and the modification of the vapour by re-evaporation are the main controls of $\delta^{18} \mathrm{O}_{\mathrm{p}}$. On the other hand, the converse would indicate that, contrary to our model, the precipitation does not re-equilibrate well with the vapour, and the conditions of rain re-evaporation as well as the condensation altitude would contribute more significantly to the observed $\delta^{18} \mathrm{O}_{\mathrm{p}}$ variations. More systematic measurements of stable water isotopes in vapour and in precipitation during field experiments focused on tropical convection, or in instrumented sites, would thus be very valuable to discriminate between these two hypotheses, and more generally to better document the evolution of rain re-evaporation and mesoscale subsidence in convective systems.

\section{Appendix}

\section{Appendix A: Tagging water and isotopic species in the 2D transport and microphysics model}

Tracking the origin of water and isotopes has been implemented in several isotopic general circulation models (Cole et al., 1999; Delaygue et al., 2000); Werner et al., 2001; Noone and Simmonds, 2002a) to determine the geographic origin of water vapour. Here, we use the same tracking concept, but for tracking altitude and reevaporation. We define $n$ altitude layers, and refer to the summit and middle of the layer $j \in[1, n]$ as $z_{\mathrm{s}}^{j}$ and $z_{\mathrm{m}}^{j}$. We consider $n=4$ layers: $0-2 \mathrm{~km}, 2-4 \mathrm{~km}, 4-6 \mathrm{~km}$, $>6 \mathrm{~km}$. We also define $n+12 \mathrm{D}$ fields $X_{\mathrm{v}}^{j}$ corresponding to vapour tracers: $n$ fields for tracking the $n$ altitude layers, and one field to track re-evaporation. At each time and in each grid box, the sum of these tracers is equal to that of the total vapour content $q_{\mathrm{v}}$ :

$$
\sum_{j=1}^{n+1} X_{\mathrm{v}}^{j}=q_{\mathrm{v}}
$$

so that the vapour can be exactly decomposed into the $n+1$ origins. Similarly, additional tracer fields are defined for the condensate and the precipitation, $q_{\mathrm{c}}$ and $q_{\mathrm{p}}$, as well as for all the isotopic species in vapour, condensate and precipitation.

In the initial state, we assume that all the vapour originates from the lowest layer: $X_{\mathrm{v}}^{j}=0$ for $j \in[2, n+$ 1] and $X_{\mathrm{v}}^{1}=q_{\mathrm{v}}$. Then, during the simulation, all tracers are advected passively like 'normal' water and isotopes, and behave similarly during phase changes. However, after advection, the following operation is performed so that tracers trace the maximum altitude encountered: at each grid point (let $z$ be the altitude of the grid point), for each of the tracer layers $j \in[1, n-1]$, if both $X_{\mathrm{V}}^{j}>0$ and $z>z_{\mathrm{s}}^{j}$ then the content of $X_{\mathrm{v}}^{j}$ is transferred to $X_{\mathrm{V}}^{j+1}$. In addition, to track the water originating from rain reevaporation, all the rain that re-evaporates, whatever its origin, is transferred to $X_{\mathrm{v}}^{n+1}$. One can thus estimate, at each grid point, the fraction of the vapour that has originated from rain re-evaporation, $r_{\mathrm{e}}$ :

$$
r_{\mathrm{e}}=\frac{X_{\mathrm{v}}^{n+1}}{q_{\mathrm{v}}} .
$$

Approximating the average altitude of the tracers in each layer by the altitude of the middle of the layer, $z_{\mathrm{m}}^{j}$, we can also estimate the maximum altitude encountered by the vapour on average, $\overline{z_{\max }}$ :

$$
\overline{z_{\max }}=\frac{\sum_{j=1}^{n}\left(X_{\mathrm{v}}^{j} z_{\mathrm{m}}^{j}\right)}{\sum_{j=1}^{n} X_{\mathrm{v}}^{j}} .
$$

Note that the estimate of $\overline{z_{\max }}$ bears uncertainties due to the heterogeneous distribution of the tracers in each altitude layer. The uncertainty is half the thickness of the layers, i.e. $1 \mathrm{~km}$. 


\section{Appendix B: Surface evaporation}

To estimate the effect of surface evaporation on the rain isotopic composition, we calculate the surface evaporation $E$ as

$$
E=\lambda(E P)
$$

with $E P$ the potential evaporation and $\lambda$ a parameter depending on the soil water $q_{\text {soil }}$. We assume that the soil becomes quickly saturated as rain falls: $\lambda=1$ when $q_{\text {soil }}>10 \mathrm{~mm}$ and $\lambda=q_{\text {soil }} / 10$ otherwise, with $q_{\text {soil }}$ in $\mathrm{mm}$. The soil water at grid point $i$ is calculated using the precipitation and evaporation rates between the beginning of the line and point $i$ :

$q_{\mathrm{soil}}(i)=\sum_{j=1}^{i}\{P(j)-E(j)\} \frac{\Delta x}{u_{\mathrm{SL}}}$,

with $P$ the precipitation rate, $u_{\mathrm{SL}}$ the advection speed of the squall line and $\Delta x$ the horizontal resolution of the model.

We calculate the potential evaporation using a Penmanlike equation (Penman (1948), used for Niger by Wallace and Holwill (1997)):

$$
E P=\frac{R_{\mathrm{n}}-G}{L_{\mathrm{v}}} \frac{\Delta}{\Delta+\gamma}+\rho \frac{1}{r}\left\{q_{\mathrm{s}}\left(T_{\mathrm{a}}\right)-q_{\mathrm{a}}\right\} \frac{\gamma}{\Delta+\gamma},
$$

with $\Delta=\left[L_{\mathrm{v}} q_{\mathrm{s}}\left(T_{\mathrm{a}}\right)\right] /\left(R_{\mathrm{d}} T_{\mathrm{a}}^{2}\right), \gamma=c_{\mathrm{p}} / L_{\mathrm{v}}, 1 / r=C_{\mathrm{d}} u$, $L_{\mathrm{v}}$ the latent heat of vaporization, $q_{\mathrm{s}}$ the specific humidity at saturation, $R_{\mathrm{d}}$ the perfect gas constant, $T_{\mathrm{a}}$ and $q_{\mathrm{a}}$ the air temperature and specific humidity in the lowest layer $(0-500 \mathrm{~m}), c_{\mathrm{p}}$ and $\rho$ the heat capacity and volumetric mass of air, $u$ the wind speed, $c_{\mathrm{d}}$ a drag coefficient set to $1.2 \times 10^{-3}, R_{\mathrm{n}}$ the net radiation and $G$ the heat flux to the soil. We neglect the presence of vegetation, which is very sparse in Niamey.

We then add this evaporated water directly into the lowest layer of the model, neglecting the effect of turbulence on vapour transport. This approximation is justified because most of the evaporation occurs in the stratiform zone associated with subsidence.

There is a large uncertainty in the calculation of the net radiation term $R_{\mathrm{n}}-G$. We thus tested two extreme values, for night-time and for midday. During the night, $R_{\mathrm{n}}$ is close to $0 \mathrm{~W} / \mathrm{m}^{2}$ or slightly negative in the Sahel (Wallace and Holwill, 1997; Guichard et al., 2008). At midday in August, $R_{\mathrm{n}}$ under clear sky is of the order of $700 \mathrm{~W} / \mathrm{m}^{2}$ (Guichard et al., 2008). During the passage of a nonprecipitating cloud system, data show a reduction of $R_{\mathrm{n}}$ by half (F. Guichard, personal communication). Assuming $G \simeq 0.4 R_{\mathrm{n}}$ (Wallace and Holwill, 1997), an upper bound for $R_{\mathrm{n}}-G$ at midday is thus about $150 \mathrm{~W} / \mathrm{m}^{2}$. We test $R_{\mathrm{n}}-G$ values between 0 and $150 \mathrm{~W} / \mathrm{m}^{2}$.

For isotopes, we calculate that the soil composition $R_{\text {soil }}$ at point $i$ using the precipitation and evaporation rates $P$ and $E$ and their compositions $R_{\mathrm{p}}$ and $R_{\mathrm{e}}$ between the beginning of the line and point $i$, in a similar way to Equation (B1). The simulated soil composition is close to the composition of the convective rain, because it is more abundant than the stratiform rain and because evaporation is negligible compared to precipitation on the scale of a squall line.

We use the Craig and Gordon (1965) equation to calculate the composition of the surface evaporation:

$$
R_{\mathrm{e}}=\frac{1}{\alpha_{\mathrm{K}}} \frac{\frac{R_{\mathrm{soil}}}{\alpha_{\mathrm{eq}}}-h R_{\mathrm{v}}}{1-h},
$$

with $h$ the relative humidity in the lowest layer, $R_{\mathrm{V}}$ the isotopic composition of the vapour and $\alpha_{\text {eq }}$ and $\alpha_{\mathrm{K}}$ the equilibrium and kinetic fractionation coefficients. We use the kinetic fractionation formulation from Mathieu and Bariac (1996):

$$
\alpha_{\mathrm{K}}=\left(\frac{D}{D^{\prime}}\right)^{n_{k}^{\prime}}
$$

with $n_{k}^{\prime}$ an exponent taking into account the ratio of molecular versus turbulent diffusivities of vapour and varying from 0.67 for saturated soil conditions to 1 in dry soils (Mathieu and Bariac, 1996). We take $n_{k}^{\prime}=0.67$, by assuming saturated soil conditions. The resulting kinetic fractionations are $\alpha_{\mathrm{K}}-1=19.0 \%$ o for $\mathrm{H}_{2}^{18} \mathrm{O}$ and $16.8 \%$ o for HDO.

The $d$-excess of the evaporation flux is highly sensitive to the formulation of the kinetic fractionation. If taking the kinetic fractionation values from Merlivat and Jouzel (1979), for example, the $d$-excess of the evaporative flux would be four times smaller.

\section{Acknowledgements}

We thank J.-P. Lafore, Aaron Boone, Françoise Guichard and J.-Y. Grandpeix for useful discussions and suggestions, M. Nuret for providing corrected RS80-A radiosoundings, S. Falourd and B. Minster for helping with the isotopic measurements, E. Williams for providing the MIT radar data, the AMMA database for providing snapshots of the MIT radar and ARM data, and two anonymous reviewers for their interesting comments and suggestions.

Based on a French initiative, AMMA was built by an international scientific group and is currently funded by a large number of agencies, especially from France, the United Kingdom, the United States and Africa. It has been the beneficiary of a major financial contribution from the European Community's Sixth Framework Research Programme. Detailed information on scientific coordination and funding is available on the AMMA International web site http://www.amma-international.org.

This work was funded by the IPSL project, AMMA API and MISTERRE programme.

\section{References}

Barras V, Simmonds I. 2009. Observation and modelling of stable water isotopes as diagnostics of rainfall dynamics over southeastern Australia. J. Geophys. Res. In press. 
Bony S, Risi C, Vimeux F. 2008. Influence of convective processes on the isotopic composition (deltaO18 and deltaD) of precipitation and water vapour in the Tropics. Part 1: Radiative-convective equilibrium and TOGA-COARE simulations. J. Geophys. Res. 113: D19305-. DOI:10.1029/2008JD009942

Caniaux G, Redelsperger JL, Lafore JP. 1994. A numerical study of the stratiform region of a fast moving squall line. Part 1: General description and water and heat budgets. J. Atm. Sci 51: 2046-2074

Celle-Jeanton H, Gonfiantini R, Travia Y, Solc B. 2004. Oxygen18 variations of rainwater during precipitation: Application of the Rayleigh model to selected rainfalls in Southern France. J. Hydrol. 289: $165-177$.

Chalon JP, Jaubert G, Lafore JP, Roux F. 1988. The West African squall line observed on 23 June 1981 during COPT 81: Mesoscale structure and transports. J. Atmos. Sci. 45: 2744-2763.

Chong M. 2009. The 11 August 2006 squall-line system as observed from MIT Doppler radar during the AMMA SOP. Q. J. R. Meteorol. Soc. 136(s1): 210-227

Chong M, Hauser D. 1990. A tropical squall line observed during the COPT81 experiment in West Africa: Part III: heat and moisture budgets. Mon. Weather Rev. 118: 1696-1706.

Cole JE, Rind D, Webb RS, Jouzel J, Healy R. 1999. Climatic controls on interannual variability of precipitation delta180 Simulated influence of temperature, precipitation amount, and vapour source region. J. Geophys. Res. 104: 14223-14236. DOI 10.1029/1999JD900182

Craig H, Gordon LI. 1965. Deuterium and oxygen-18 variations in the ocean and marine atmosphere. Stable Isotope in Oceanographic Studies and Paleotemperatures.

Dansgaard W. 1964. Stable isotopes in precipitation. Tellus 16: 436-468

Delaygue G, Masson V, Jouzel J, Koster RD, Healy RJ. 2000. The origin of Antarctic precipitation: A modelling approach. Tellus 52B 19-36

Dessler AE, Sherwood SC. 2003. A model of HDO in the tropical tropopause layer. Atmos. Chem. Phys. 3: 2173-2181.

Emanuel KA. 1991. A scheme for representing cumulus convection in large-scale models. J. Atmos. Sci. 48: 2313-2329.

Fudeyasu H, Ichiyanagi K, Sugimoto A, Yoshimura K, Ueta A Yamanaka MD, Ozawa K. 2008. Isotope ratios of precipitation and water vapour observed in Typhoon Shanshan. J. Geophys. Res. 113 D12 113-. DOI:10.1029/2007JD009313

Gedzelman S, Lawrence J, Gamache J, Black M, Hindman E, Black R, Dunion J, Willoughby H, Zhang X. 2003. Probing hurricanes with stable isotopes of rain and water vapour. Mon. Weather Rev. 131 $112-1127$.

Gonfiantini R, Roche MA, Olivry JC, Fontes JC, Zuppi GM. 2001. The altitude effect on the isotopic composition of tropical rains. Chem. Geol. 181: 147-167.

Guichard F, Kergoat L, Mougin E, Timouk F, Baup F, Hiernaux P Lavenu F. 2008. Surface thermodynamics and radiative budge in the Sahelian Gourma: Seasonal and diurnal cycles. J. Hydrol DOI:10.1016/j.jhydrol.2008.09.007

Hauser D, Roux F, Amayenc P. 1988. Comparison of two methods for the retrieval of thermodynamic and microphysical variables from Doppler radar measurements: application to the case of a tropical squall line. J. Atmos. Sci. 45: 1285-1303.

Hoffmann G, Werner M, Heimann M. 1998. Water isotope module of the ECHAM atmospheric general circulation model: A study on timescales from days to several years. J. Geophys. Res. 103 16871-16896. DOI: $10.1029 / 98 J D 00423$

Houze RA. 1977. Structure and dynamics of a tropical squall line system. Mon. Weather Rev. 105: 1540-1567.

Janicot S, Thorncroft D, Ali A, Asencio N, coauthors. 2008. Largescale overview of the summer monsoon over West and Central Africa during the AMMA field experiment in 2006. Ann. Geophys. 26 2569-2595.

Jouzel J, Koster R, Suozzo R, Russell G, White J, Broecker W. 1991. Simulations of the HDO and H2O-18 atmospheric cycles using the NASA GISS general circulation model: Sensitivity experiments for present-day conditions. J. Geophys. Res. 96: 7495-7507.

Kessler E. 1969. On the distribution and continuity of water substance in atmospheric circulation. Meteorol. Monographs 32: 84

Lafore JP, Redelsperger JL, Jaubert G. 1988. Comparison between a three-dimensional simulation and Doppler radar data of a tropica squall line: Transports of mass, momentum, heat and moisture. J. Atmos. Sci. 45: 3483-3500.
Lee JE, Fung I. 2008. 'Amount effect' of water isotopes and quantitative analysis of post-condensation processes. Hydrol. Processes 22: 1-8.

Lee JE, Fung I, DePaolo D, Fennig CC. 2007. Analysis of the global distribution of water isotopes using the NCAR atmospheric general circulation model. J. Geophys. Res. 112 . D16306. DOI:10.1029/2006JD007 657

Mathieu R, Bariac T. 1996. A numerical model for the simulation of stable isotope profiles in drying soils. J. Geophys. Res. 101: 12685-12696.

Merlivat L, Jouzel J. 1979. Global climatic interpretation of the Deuterium-Oxygen 18 relationship for precipitation. J. Geophys. Res. 84: 5029-5332.

Moyer EJ, Irion FW, Yung YL, Gunson MR. 1996. ATMOS stratospheric deuterated water and implications for troposphere-stratosphere transport. Geophys. Res. Lett. 23: 2385-2388. DOI: $10.1029 / 96 G L 01489$

Noone D, Simmonds I. 2002a. Annular variations in moisture transport mechanisms and the abundance of deltaO18 in Antarctic snow. J. Geophys. Res. 107: 4742. DOI:4710.1029/2002JD002 262

Noone D, Simmonds I. 2002b. Associations between delta180 of water and climate parameters in a simulation of atmospheric circulation for 1979-95. J. Climate 15: 3150-3169.

Nuret M, Lafore JP, Guichard F, Redelsperger JL, Bock O, AugustiPanareda A, N'Gamini JB. 2008. Correction of humidity bias for Vaisala RS80-A sondes during the AMMA 2006 observing period. J. Atmos. Oceanic Technol. 25: 2152-2158.

Penman HL. 1948. Natural evaporation from open water, bare soil and grass. Proc. R. Soc. London Ser. A 193: 120-145.

Pierrhumbert RT, Roca R. 1998. Evidence for control of Atlantic subtropical humidity by large scale advection. Geophys. Res. Lett. 25: $4537-4540$

Redelsperger JL, Lafore JP. 1987. A three dimensional simulation of a tropical squall line: Convective organisation and thermodynamic vertical transport. J. Atmos. Sci. 47: 1334-1356.

Redelsperger JL, Thorncroft C, Arona D, Lebel T, Parker D, Polcher J. 2006. African Monsoon Multidisciplinary Analysis: An international research project and field campaign. Bull. Am. Meteorol. Soc. 87: $1739-1746$

Rindsberger M, Jaffe S, Rahamim S, Gat R. 1990. Patterns of the isotopic composition of precipitation in time and space: Data from the Israeli storm water collection program. Tellus 42: 263-271.

Risi C, Bony S, Vimeux F. 2008a. Influence of convective processes on the isotopic composition (O18 and $\mathrm{D})$ of precipitation and water vapour in the Tropics: Part 2: Physical interpretation of the amount effect. J. Geophys. Res. 113.

Risi C, Bony S, Vimeux F, Descroix L, Ibrahim B, Lebreton E, Mamadou I, Sultan B. 2008b. What controls the isotopic composition of the African monsoon precipitation? Insights from event-based precipitation collected during the 2006 AMMA campaign. Geophys. Res. Lett. 35: DOI:10.1029/2008GL035920

Sherwood SC, Wahrlich R. 1999. Observed evolution of tropical deep convective events and their environment. Mon. Weather Rev. 127: $1777-1795$.

Stewart MK. 1975. Stable isotope fractionation due to evaporation and isotopic exchange of falling waterdrops: Applications to atmospheric processes and evaporation of lakes. J. Geophys. Res. 80: 1133-1146.

Taupin JD, Gallaire R. 1998. Variabilité isotopique à I'échelle infra-événement de quelques épisodes pluvieux dans la région de Niamey, Niger. C.R.A.S. 326: 493-498.

Tindall JC, Valdes P, Sime LC. 2009. Stable water isotopes in HadCM3: Isotopic signature of El Nino-Southern Oscillation and the tropical amount effect. J. Geophys. Res. 114: D04111-. DOI:04 110.01 029/02 008JD010 825

Wallace J, Holwill C. 1997. Soil evaporation from Tiger-bush in southwest Niger. J. Hydrol. 188-189: 426-442.

Webster CR, Heymsfield AJ. 2003. Water isotope ratios D/H, 18O/16O, $17 \mathrm{O} / 16 \mathrm{O}$ in and out of clouds map dehydration pathways. Science 302: $1742-1746$. DOI: $10.1126 /$ science. 1089496

Werner M, Heimann M, Hoffmann G. 2001. Isotopic composition and origin of polar precipitation in present and glacial climate simulations. Tellus 53B: 53-71. DOI: 10.1034/j.16000889.2001.01154.x

Williams E, Rutledge SA, Geotis SG, Renno N, Rsmussen E, Rickenbach T. 1992. A radar and electrical study of Tropical 'hot towers'. J. Atmos. Sci. 49: 1386-1395. 
Worden J, Noone D, Bowman K. 2007. Importance of rain evaporation and continental convection in the tropical water cycle. Nature 445 : $528-532$.

Zahiri EP. 2007. 'Cycle de l'eau des systèmes convectifs ouestafricains: preparation à l'exploitation des mesures radar xport dans amma par simulations'. $\mathrm{PhD}$ thesis. Université Paul Sabatier - Toulouse III: Toulouse.
Zipser E. 1977. Mesoscale and convective scale downdrafts as distinct components of squall-line structure. Mon. Weather Rev. 105: $1568-1589$. 